\title{
PERFORMANCE DEMONSTRATION PROGRAM PLAN FOR NONDESTRUCTIVE ASSAY OF BOXED WASTES FOR THE TRU WASTE CHARACTERIZATION PROGRAM
}

\author{
Revision 0
}

January 31, 2001

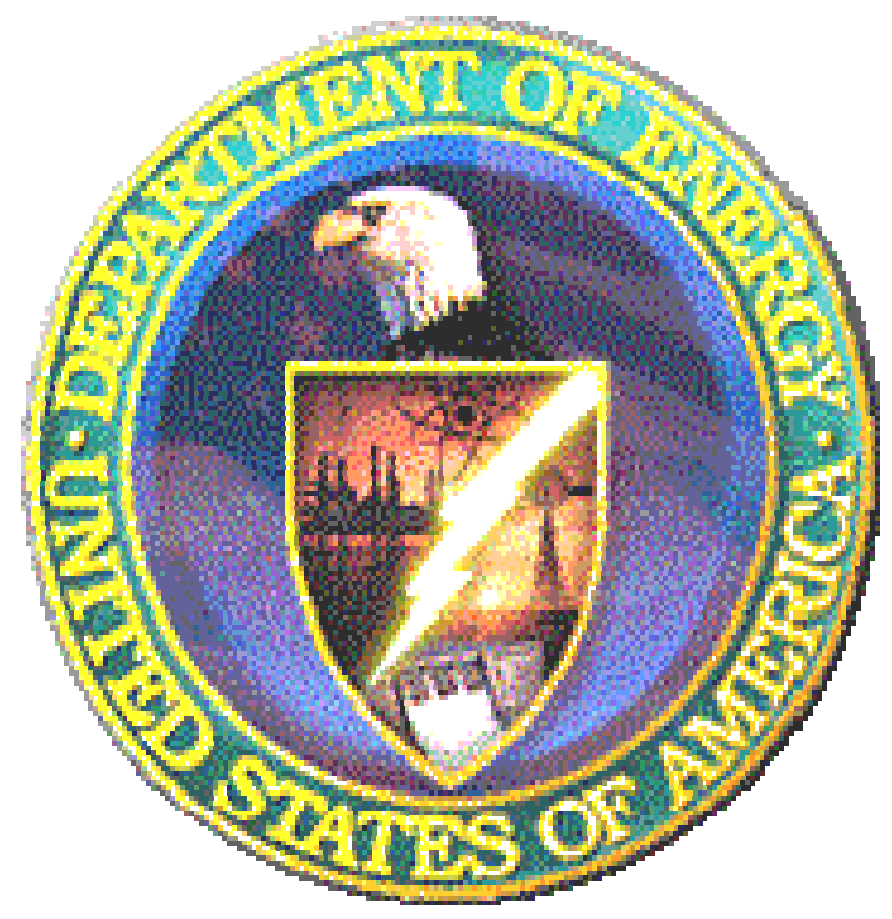

U.S. Department of Energy

Carlsbad Field Office

Office of the National TRU Program 
This document has been submitted as required to:

Office of Scientific and Technical Information

PO Box 62

Oak Ridge, TN 37831

(615) 576-8401

Additional information about this document may be obtained by calling 1-800-336-9477. Copies may be obtained by contacting the National Technical Information Service, US Department of Commerce, 5285 Port Royal Road, Springfield, VA 22101. 


\title{
Performance Demonstration Program Plan for Nondestructive Assay of Boxed Wastes for the TRU Waste Characterization Program
}

\author{
DOE/CBFO-01-1006 \\ Revision 0
}

January 31, 2001

\begin{abstract}
Approved By:
Team Leader

National TRU Waste Certification Team

Date:

Concurred By:

Team Leader

Quality Assurance

Date:
\end{abstract}

Prepared By:

Manager - Waste Characterization/Certification

National TRU Waste Certification Team

Date: 


\section{TABLE OF CONTENTS}

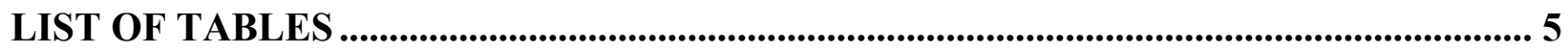

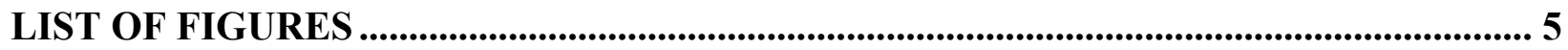

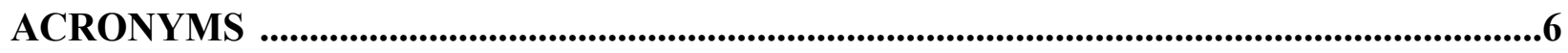

1.0 INTRODUCTION

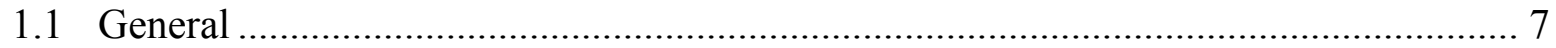

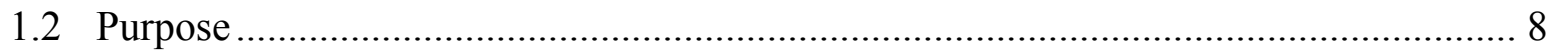

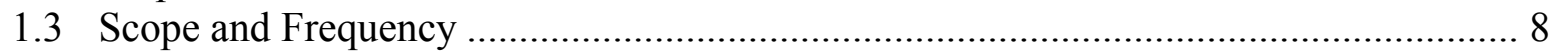

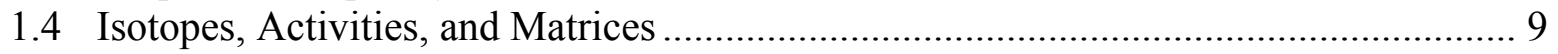

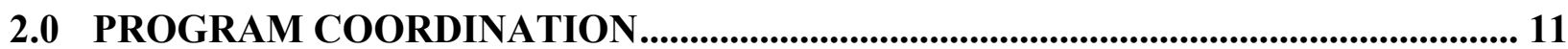

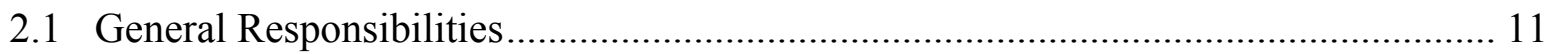

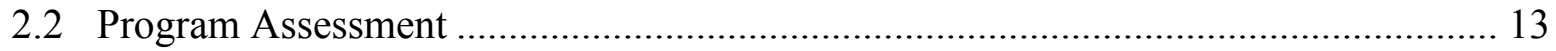

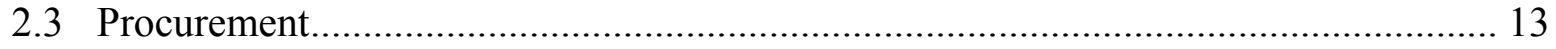

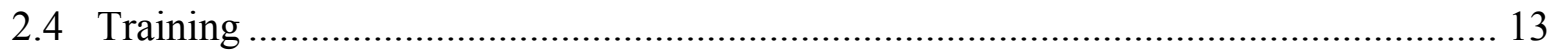

3.0 PREPARATION AND DISTRIBUTION OF RADIOACTIVE STANDARDS AND BOXED WASTE SURROGATES ............................................................... 14

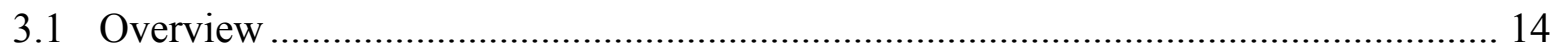

3.2 PDP Sample Components Receipt …......................................................... 17

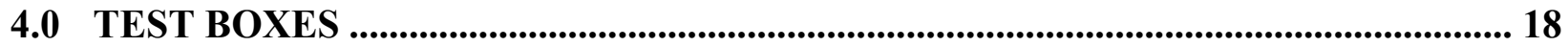

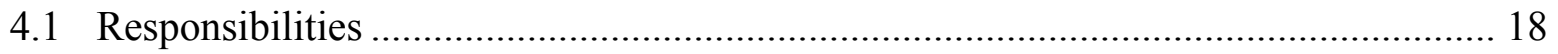

4.2 Instructions for PDP Sample Preparation ...................................................... 19

5.0 ANALYTICAL AND DATA REPORTING REQUIREMENTS ................................ 22

5.1 Simulated Waste Container Acceptance ............................................................... 22

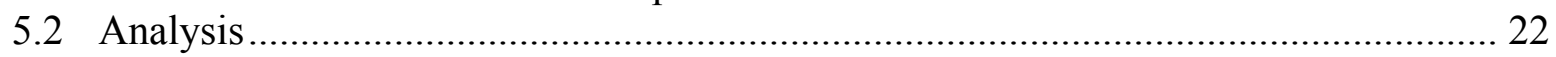

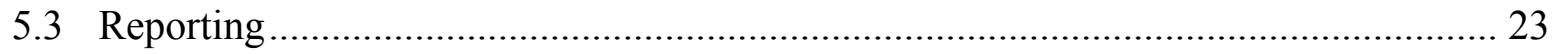

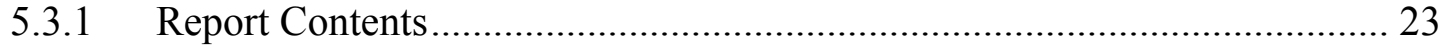

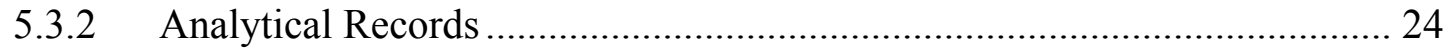

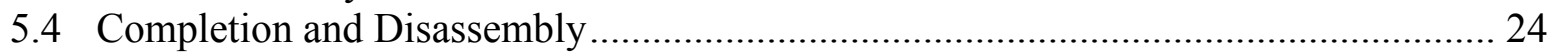

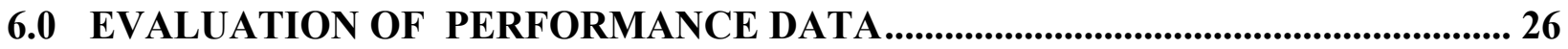

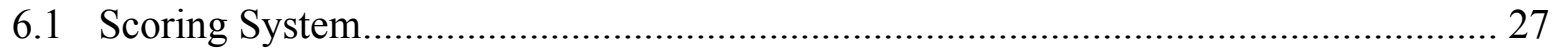

6.1.1 Bias of Quantitation of Simulated TRU Wastes ...................................... 28

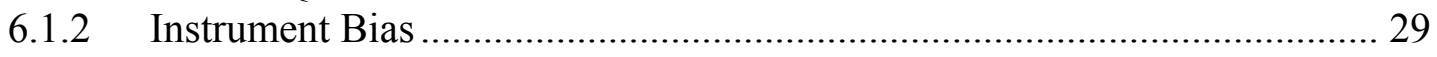

6.1.3 Precision of Replicate Determinations .............................................. 30

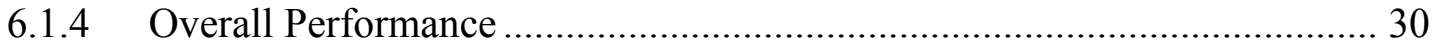


7.0 REPORTING OF PERFORMANCE DATA............................................................... 33

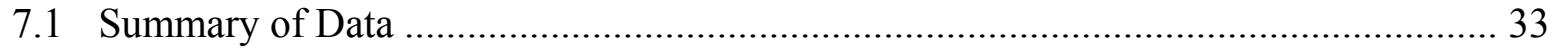

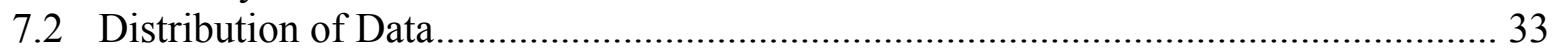

7.3 Backup PDP Samples ................................................................................... 33

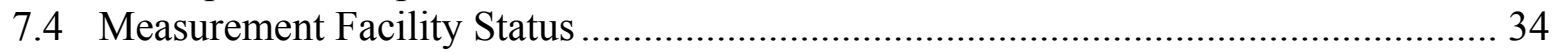

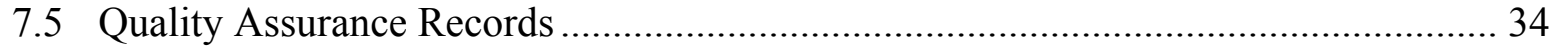

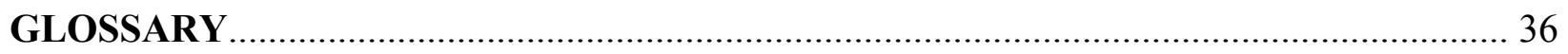

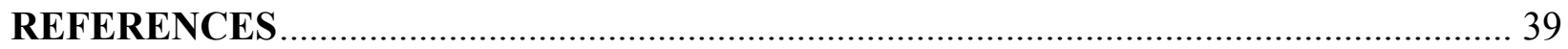

APPENDIX A Criteria for Identical Assay Systems for the NDA Box PDP ..................... 40

APPENDIX B Performance Demonstration Program for NDA of Boxed

Wastes NDA System Registration Form .............................................. 43

APPENDIX C Statistical Basis for Scoring Criteria........................................................ 48

APPENDIX D Specifications for Radioactive PDP Standards ........................................ 55

APPENDIX E SWB Matrix Surrogate Specifications.................................................... 58

APPENDIX F Performance Demonstration Program Forms ......................................... 64

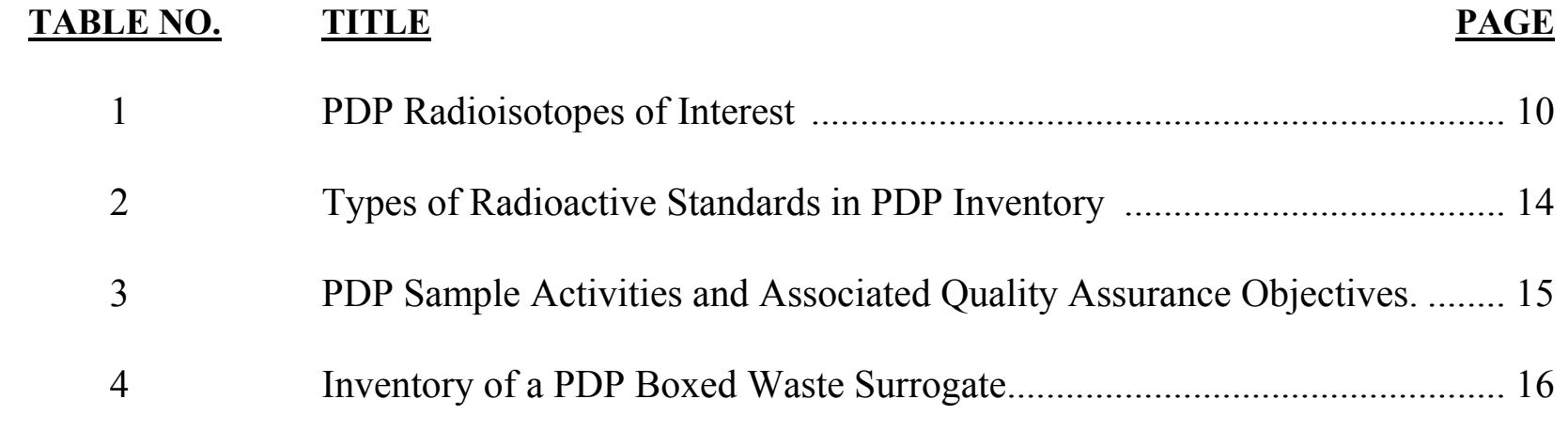

\section{FIGURE NO.}

LIST OF FIGURES
PAGE

$1 \quad$ Organization and Information Flow for the NDA Box PDP …................... 12 


\section{ACRONYMS}

\%R percent recovery

\%RSDpercent relative standard deviation

CBFO Carlsbad Field Office

DOE U.S. Department of Energy

EDR electronic data recorder

FGE fissile gram equivalent

HSG headspace gas

IWG Interface Working Group

LLW low-level waste

NDA nondestructive assay

NTWCT National TRU Waste Certification Team

PDP Performance Demonstration Program

QA quality assurance

QAO quality assurance objective

QAPD Quality Assurance Program Document

RCRA Resource Conservation and Recovery Act

SNM special nuclear material

SOP standard operating procedure

SPT sample preparation team

SWB standard waste box

TID tamper-indicating device

TRU transuranic

WG Pu weapons-grade plutonium

WG $\mathrm{PuO}_{2}$ weapons-grade plutonium dioxide

WAC Waste Acceptance Criteria for the Waste Isolation Pilot Plant

WIPP Waste Isolation Pilot Plant

VTSR validated time of sample receipt 


\subsection{INTRODUCTION}

\subsection{General}

The Performance Demonstration Program (PDP) for nondestructive assay (NDA) consists of a series of tests to evaluate the capability for NDA of transuranic (TRU) waste throughout the Department of Energy (DOE) complex. Each test is termed a PDP cycle. These evaluation cycles provide an objective measure of the reliability of measurements obtained from NDA systems used to characterize the radiological constituents of TRU waste.

The primary documents governing the conduct of the PDP are the Waste Acceptance Criteria for the Waste Isolation Pilot Plant (WAC; DOE 1999a) and the Quality Assurance Program Document (QAPD; DOE 1999b). The WAC requires participation in the PDP; the PDP must comply with the QAPD and the WAC. The WAC contains technical and quality requirements for acceptable NDA. This plan implements the general requirements of the QAPD and applicable requirements of the WAC for the NDA PDP for boxed waste assay systems.

Measurement facilities demonstrate acceptable performance by the successful testing of simulated waste containers according to the criteria set by this PDP Plan. Comparison among DOE measurement groups and commercial assay services is achieved by comparing the results of measurements on similar simulated waste containers reported by the different measurement facilities. These tests are used as an independent means to assess the performance of measurement groups regarding compliance with established quality assurance objectives (QAO's). Measurement facilities must analyze the simulated waste containers using the same procedures used for normal waste characterization activities.

For the boxed waste PDP, a simulated waste container consists of a modified standard waste box (SWB) emplaced with radioactive standards and fabricated matrix inserts. An SWB is a waste box with ends designed specifically to fit the TRUPACT-II shipping container. SWB's will be used to package a substantial volume of the TRU waste for disposal. These PDP sample components are distributed to the participating measurement facilities that have been designated and authorized by the Carlsbad Field Office (CBFO). The NDA Box PDP materials are stored at these sites under secure conditions to protect them from loss, tampering, or accidental damage.

Using removable PDP radioactive standards, isotopic activities in the simulated waste containers are varied to the extent possible over the range of concentrations anticipated in actual waste characterization situations. Manufactured matrices simulate expected waste matrix configurations and provide acceptable consistency in the sample preparation process at each measurement facility. Analyses that are required by the Waste Isolation Pilot Plant (WIPP) to demonstrate compliance with various regulatory requirements and that are included in the PDP may only be performed by measurement facilities that demonstrate acceptable performance in the PDP. These analyses are referred to as WIPP analyses, and the wastes on which they are performed are referred to as WIPP wastes in this document. 


\subsection{Purpose}

The purpose of the NDA Box PDP is to demonstrate the ability of DOE facilities (including owned or contracted mobile systems, if applicable) to meet the data quality objectives for NDA of wastes intended for disposal at WIPP. The CBFO will use the PDP as one part of the assessment and approval process for the measurement facilities supplying services for the characterization of WIPP TRU waste. The process includes evaluating method performance data submitted by the measurement facility and performing quality assurance audits.

This NDA Box PDP Plan describes the detailed elements that the program comprises, including the nature of the test materials and the analyses required. A separate document, the Performance Demonstration Program Plan for Nondestructive Assay of Drummed Wastes for the TRU Waste Characterization Program (DOE 2001a), describes the analogous program for 55-gallon drum assay systems. The two NDA PDP's closely parallel one another in all respects, including having the same QAO's. This Box PDP Plan, like the Drum PDP Plan, also identifies the criteria that are used to evaluate measurement facility performance and the responsibilities of the program participants, including the NDA PDP coordinator, contractors producing radioactive standards and waste matrix surrogates, sample preparation teams (SPT's), and the individual measurement facilities. The CBFO ensures the implementation of the plan by designating a program coordinator and by providing technical oversight and coordination for the program. In addition to this PDP and the Drum PDP, there are two other PDP's that are described in two additional PDP plans: Performance Demonstration Program Plan for RCRA Constituent Analysis of Solidified Wastes (DOE 2001b) and Performance Demonstration Program Plan for the Analysis of Simulated Headspace Gases for the TRU Waste Characterization Program (DOE 2001c).

\subsection{Scope and Frequency}

Acceptable performance must be demonstrated initially by a participating measurement facility. Subsequently, the WAC (DOE 1999a) requires that all participating measurement facilities be evaluated periodically as specified in this PDP Plan. The primary cycle for PDP participation will be annual (i.e., every twelve months \pm one month). In addition to the primary test cycle, the NDA PDP coordinator may design a second set of similar simulated waste containers for use in a supplemental cycle. Similar test configurations are maintained where possible to provide approximately equivalent test opportunities for the participants. Additional special supplemental cycles may be conducted on an as-needed basis at CBFO's direction.

Participation of NDA systems in the NDA Box PDP is required according to the following general rules, unless a specific exemption is granted by $\mathrm{CBFO}$ :

- All active systems must participate in the primary cycle of an NDA PDP.

- Inactive and out-of-service systems are not required to participate in scheduled cycles of the NDA PDP as long as they remain in an inactive or out-of-service condition. 
- All systems that have been inactive for a period including a scheduled PDP cycle must participate in a cycle of the NDA PDP prior to returning to active status. If this does not coincide with the timing of a primary or supplemental cycle of the PDP, the owner/operator should request a special supplemental cycle. Affected DOE sites may incorporate a special supplemental cycle in the acceptance testing of a system when deployed at the site.

- All out-of-service systems must demonstrate acceptable method performance prior to any waste characterization activities. These systems must then participate in the next scheduled cycle of the NDA PDP.

- If a facility is operating two or more identical systems, only one system needs to participate in any given PDP cycle. The site assay coordinator shall rotate participation in consecutive PDP cycles among identical systems. Each manufacturer or owner/operator making a claim of identical systems shall submit a document to the NDA PDP coordinator identifying the systems and addressing each of the criteria used to define identical systems. Definitions of active, inactive, and out-of-service systems are listed in the Glossary. Appendix A contains the criteria that define identical assay systems for the purpose of participation in the NDA Box PDP.

- If an assay system has more than one mode for producing quantitative assay data, the NDA PDP coordinator may design additional test configurations in the PDP cycle for that specific system to ensure that all modes are included in the PDP. The design of the additional test configurations that target specific assay modes will be based on the information supplied on the registration forms submitted for the system. (See appendix B.)

The criteria for acceptable performance are given in section 6 of this PDP Plan. The PDP samples must be analyzed using the methods the measurement facility anticipates using for the analysis of WIPP wastes. Only the methods actually used in the PDP are considered acceptable to support the analysis of WIPP wastes. The data generated as a result of the performance demonstration indicate the appropriateness of the method used, as well as the performance of the measurement facility.

\subsection{Isotopes, Activities, and Matrices}

The isotopes to be analyzed under this PDP Plan are presented in table 1. Of these, the first four are the most significant in terms of WIPP inventory, potential releases for 10,000 years, and ensuring safe transportation. The last three, isotopes of uranium, may be significant at some sites. Therefore, PDP standards of depleted and/or enriched uranium have been made available at selected sites for PDP tests.

In addition to the radioactive standard support and access structure, the SWB's used for the PDP tests contain manufactured matrix inserts. These manufactured matrices are designed to 
Table 1. PDP Radioisotopes of Interest

\begin{tabular}{lc}
\hline 1. & Isotope \\
2. & ${ }^{238} \mathrm{Pu}$ \\
3. & ${ }^{230} \mathrm{Pu}$ \\
4. & ${ }^{241} \mathrm{Au}$ \\
& ${ }^{243} \mathrm{Um}$ \\
5. & ${ }^{233} \mathrm{U}$ \\
6. & ${ }^{234} \mathrm{U}$ \\
\hline
\end{tabular}

simulate the physical properties of real waste forms and their associated perturbations of NDA system response. The TRU waste forms distributed across the DOE facilities display a broad spectrum of waste types. It is intended that the PDP tests include sufficient different simulated waste forms to test a broad range of measurement conditions expected to be encountered in assaying actual waste forms.

The designs of the matrix inserts have been developed from consultations with those sites most likely to generate large volumes of waste that will be packaged for the WIPP in SWB's. The designs simulate properties of the actual waste through the use of materials as similar as possible to representative waste in composition, density, and physical form. In addition to the principal components of the waste, the designs specifically include the capability for simulating:

- Voids in the waste

- Mixtures with large volumes or weights of waste other than the nominal, principal waste form(s), and

- Nonrandom, geometric distributions of waste

Nonrandom distributions include, but are not limited to, practices such as topping off waste boxes with disposable clothing, plastic sheeting, and other consumables used during waste packaging. The surrogate design accommodates source insert fixtures for the introduction and precise location of radioactive standards. Subsequent sections of this document describe additional details of the program implementation. 


\subsection{PROGRAM COORDINATION}

\subsection{General Responsibilities}

The CBFO is the reviewing and approving authority for the PDP. Programmatic direction and oversight of the PDP are performed by the National TRU Waste Certification Team (NTWCT), which manages the PDP on behalf of the CBFO. The NTWCT is part of the Office of the National TRU Program. Figure 1 summarizes the organizational flow of the NDA Box PDP.

The PDP is conducted periodically as described in this document. A CBFO-designated organization functions as the program coordinator and technical advisor to CBFO. The program coordinator shall meet all of the responsibilities assigned by this plan in accordance with the requirements of the CBFO Performance Demonstration Program Management Plan (DOE 2001d). For the NDA Box PDP, the NDA PDP coordinator is responsible for the following:

- Ensures preparation, control, and distribution of PDP standards and matrix surrogates

- Distributes PDP cycle schedules to facility participants

- Confirms the scheduling of a PDP cycle at least 2 weeks before the planned start date

- Develops ongoing procedures for PDP sample preparation for standards emplacement and removal, on-site PDP sample certification, and the security and confidentiality of the active SWB surrogate test configurations

- Provides training for the on-site SPT's

- Receives, reviews, and compiles the analytical data

- Reports performance data as specified within this document

- Ensures that the records of participation and results of all PDP cycles are maintained in a traceable and retrievable condition

- Reviews any changes in the QAPD or WAC that affect the PDP or this plan; revises the plan when necessary

The NDA PDP coordinator provides technical oversight and coordination of the demonstration program to qualify participating measurement facilities and maintains a current list of the facilities participating in the testing program. The NDA PDP coordinator maintains a registration and tracking system for the measurement systems that are tested in the NDA Box PDP. The registration system records the following for each assay system: a unique identity, operating principles and modes, test history by activity ranges and matrix types, the PDP test combinations permitted under calibration and administrative limits, and any other system information required by $\mathrm{CBFO}$. 


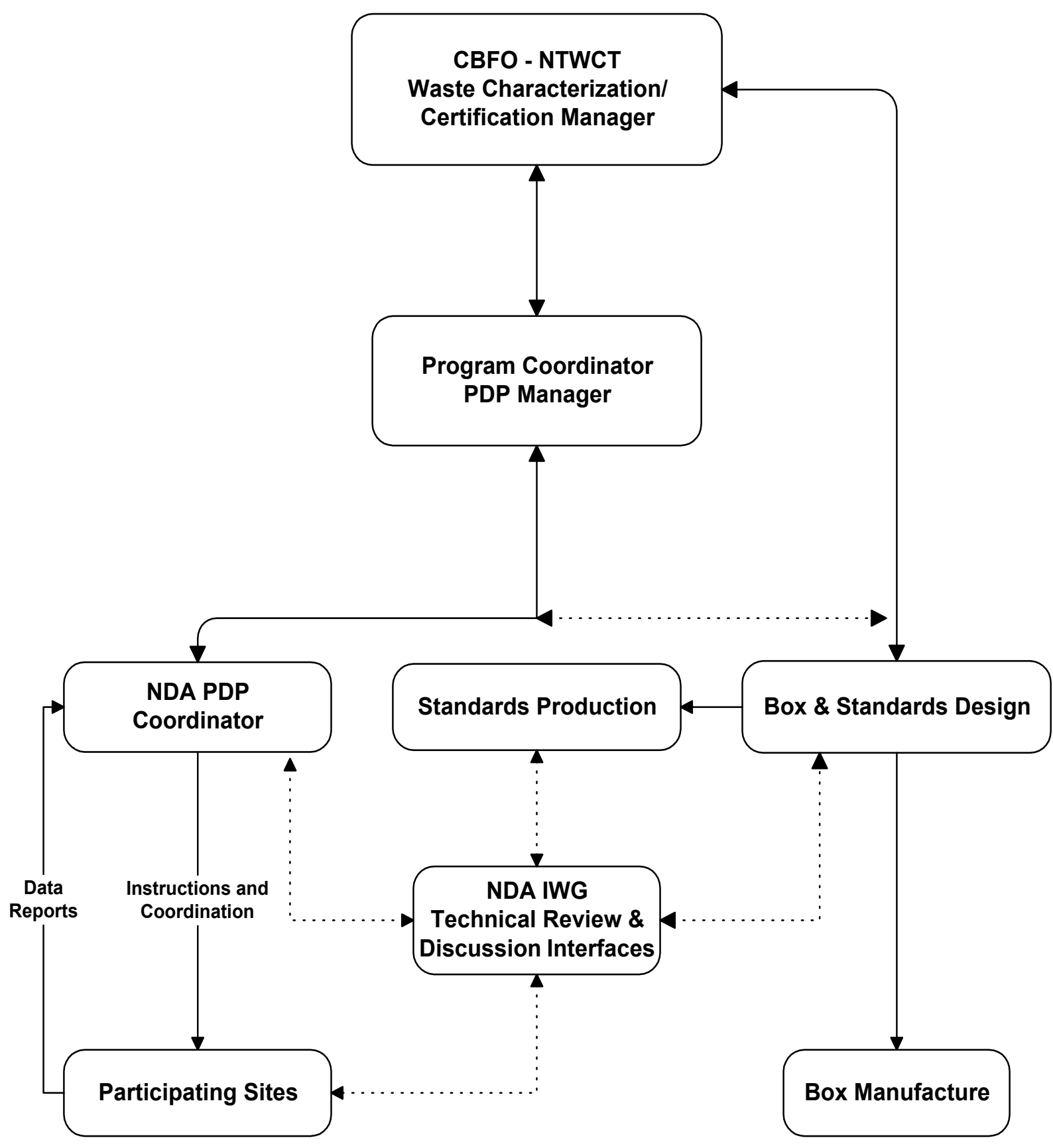

Figure 1. Organization and Information Flow for the NDA Box PDP 
The CBFO must grant written approval for each facility/system to be a participant in this PDP. Facilities/systems that are not current participants may petition the CBFO to be permitted to participate in the PDP. Participation by measurement facilities not actively engaged in characterization of TRU wastes for WIPP-related programs is at the discretion of the CBFO, and the participant must provide funding for such involvement.

Each participating facility is required to provide the NDA PDP coordinator with the name, telephone number, fax number, and address of the contact persons responsible for administrative communications for the PDP. Each participating facility is also required to provide a contact and address suitable for delivery by freight and package delivery service for the matrix surrogates and the PDP standards. Participants must complete a registration form for each measurement system to be tested in the NDA Box PDP to establish its identification, calibration range for test matrices, and other administrative limits affecting the acceptable ranges of PDP testing. Appendix B contains the necessary form and instructions for registering a boxed waste NDA system for the NDA PDP. The form must be completed and forwarded to the NDA PDP coordinator at least three weeks before participation in the NDA Box PDP.

\subsection{Program Assessment}

The PDP is routinely assessed for efficacy and appropriateness through several interrelated activities. These activities include the NTWCT's review and acceptance of the final testing results for each PDP cycle, as well as their review and approval of this plan. In order to assess the ongoing effectiveness of the PDP, the NTWCT also considers reports and observations of the program coordinator, PDP manager, and NDA PDP coordinator; feedback from program participants; and comments from other parties such as independent quality assurance (QA) assessors, the TRU Waste Steering Committee, and the Nondestructive Assay Interface Working Group (IWG). Such communications may take any documented form, including, but not limited to, routine program correspondence, meeting minutes, action items, formal review of program documents, assessment reports, and corrective action requests.

\subsection{Procurement}

Procurement activities necessary for conducting the PDP must comply with the QAPD. In accordance with the QAPD, the responsible purchasing organization maintains all procurement documents and performs all procurement activities.

\subsection{Training}

Each organization involved in conducting the PDP shall meet the training requirements of the QAPD. Organizations shall retain on file evidence that 1) personnel have the necessary program documents (controlled or uncontrolled, as applicable) for their use and 2) personnel have read and understand program-governing documents pertinent to their duties in supporting the PDP. At a minimum, these documents include the QAPD, the WAC, and this plan. 


\subsection{PREPARATION AND DISTRIBUTION OF RADIOACTIVE STANDARDS AND BOXED WASTE SURROGATES}

\subsection{Overview}

The CBFO is responsible for specifying and procuring PDP standards. A PDP standard is defined as a radioactive source specifically designed, prepared (or acquired), and certified for the PDP. PDP standards will be obtained from suppliers who maintain measurement systems traceable to the National Institute of Standards and Technology. The standards used in the NDA Box PDP have been manufactured specifically for the program. However, certified sources from existing programs and commercial sources may be used if the specifications meet a specific program need.

The number of standards and the amount of special nuclear material (SNM) inserted in each boxed waste surrogate are selected from a larger inventory of PDP standards at each site. The subset selected for each test configuration is chosen so as to prevent inference of the contained material by the measurement facility assay team. The types of radioactive materials in the inventory include those listed in table 2.

Table 2. Types of Radioactive Standards in PDP Inventory

1. Weapons grade plutonium

2. Uranium, highly enriched

3. Uranium, depleted

4. Enhanced $\mathrm{Am} / \mathrm{Pu}$ ratio (relative to the initial values in weapons grade plutonium)

5. Increased particle size (relative to the material distributed in type number 1)

Identified ranges to which the QAO's apply for standard boxed waste activities under this PDP Plan are listed in table 3. See section 6 and appendix $C$ for explanations of the statistical basis for the differences between the idealized QAO's in table 3 and the PDP criteria for the measured precision data. The geometry of the PDP standards is compatible with PDP matrix insert fixtures to allow secure and accurate placement within the boxed waste surrogates. Refer to appendix D for detailed specifications for PDP radioactive standards.

The CBFO is also responsible for specifying and procuring a series of boxed waste surrogates for use in the NDA Box PDP. A complete inventory of a boxed waste surrogate is given in table 4. Only two different waste matrix surrogates are used in the routine boxed waste PDP tests. These two forms are sufficient to test for characterization of the waste types normally packaged in SWB's for disposal at WIPP. 
Table 3. PDP Sample Activities and Associated Quality Assurance Objectives

\begin{tabular}{|c|c|c|c|c|c|c|}
\hline \multirow[b]{2}{*}{$\begin{array}{l}\text { Activity } \\
\text { range }\end{array}$} & \multirow[b]{2}{*}{$\begin{array}{l}\text { Range of } \\
\text { waste activity } \\
\text { in } \alpha \text {-curies }{ }^{\mathrm{a}}\end{array}$} & \multirow[b]{2}{*}{$\begin{array}{l}\text { QAO for } \\
\text { precision } \\
(\% \text { RSD })\end{array}$} & \multicolumn{2}{|c|}{$\begin{array}{l}\text { Maximum measured } \\
\text { precision }^{c}\end{array}$} & \multicolumn{2}{|c|}{$\begin{array}{c}\text { Bias }^{\mathrm{d}} \\
\left(\% \mathrm{R}_{\mathrm{L}} \text { and } \% \mathrm{R}_{\mathrm{H}} \text { in equation } 3\right)\end{array}$} \\
\hline & & & $\begin{array}{c}\text { Noninterfering } \\
\text { matrix } \\
(\% \mathrm{RSD})\end{array}$ & $\begin{array}{c}\text { Interfering } \\
\text { matrix } \\
(\% \mathrm{RSD})\end{array}$ & $\begin{array}{c}\text { Noninterfering } \\
\text { matrix } \\
(\% \mathrm{R})\end{array}$ & $\begin{array}{c}\text { Interfering } \\
\text { matrix } \\
(\% \mathrm{R})\end{array}$ \\
\hline Low & $>0$ to 0.02 & $29.2 \%$ & $14 \%$ & $16 \%$ & $\begin{array}{l}\text { Low: } 70 \% \\
\text { High: } 130 \%\end{array}$ & $\begin{array}{l}\text { Low: } 40 \% \\
\text { High: } 160 \%\end{array}$ \\
\hline Mid-Low & $>0.02$ to 0.2 & $21.9 \%$ & $10.5 \%$ & $12 \%$ & $\begin{array}{l}\text { Low: } 70 \% \\
\text { High: } 130 \%\end{array}$ & $\begin{array}{l}\text { Low: } 40 \% \\
\text { High: } 160 \%\end{array}$ \\
\hline Mid-High & $>0.2$ to 2.0 & $14.6 \%$ & $7 \%$ & $12 \%$ & $\begin{array}{l}\text { Low: } 70 \% \\
\text { High: } 130 \%\end{array}$ & $\begin{array}{l}\text { Low: } 40 \% \\
\text { High: } 160 \%\end{array}$ \\
\hline High & $>2.0$ & $7.3 \%$ & $3.5 \%$ & $6 \%$ & $\begin{array}{l}\text { Low: } 70 \% \\
\text { High: } 130 \%\end{array}$ & $\begin{array}{l}\text { Low: } 40 \% \\
\text { High: } 160 \%\end{array}$ \\
\hline
\end{tabular}

$\% \mathrm{R}=$ percent recovery; $\% \mathrm{RSD}=$ percent relative standard deviation.

a. Applicable range of TRU activity in an SWB to which the QAO's apply; units are curies of alpha-emitting TRU isotopes with half-lives greater than 20 years.

b. Limits for one relative standard deviation, $s / \overline{\mathrm{X}}$, expressed as a percent; precision is equal to the standard deviation of the underlying measurement distribution. See section 6.1

c. Measured precisions that must be met to satisfy the precision criteria at the 95 percent upper confidence bound, based on six replicates. The values are one relative standard deviation referenced to the known (or accepted) value for the test, not to the mean of the measurements, $s / \mu$.

d. Limits on the two-sided, 95 percent confidence bound for the ratio of the mean of the measured values to the known (or accepted) value, expressed as a percent.

Refer to appendix E for detailed specifications on the boxed waste surrogate design. This appendix illustrates the design and construction features of the boxed waste surrogate components. Test SWB's are constructed by inserting simulated matrix materials of appropriate weight and distribution throughout the open volume of the boxed waste surrogate housing. The NDA PDP coordinator will ensure that detailed specifications for the boxed waste surrogates are made available to program participants.

The NDA PDP coordinator shall ensure delivery of the PDP standards and boxed waste surrogates to each measurement facility prior to the start of that facility's participation in PDP measurement activities. The NDA PDP coordinator will provide instructions for the care and storage of the boxed waste surrogates. The measurement facility is responsible for assigning an appropriate and secure storage area for the surrogate components. Failure to follow the care and storage instructions could result in damage to or adverse changes in the composition of the surrogate matrix materials. This could compromise the integrity and/or usefulness of the surrogates for subsequent PDP tests. Each set of boxed waste surrogates is as identical as possible. The matrix inserts are individually serial numbered. Each contains known quantities of waste simulating materials in precise locations. No one is authorized to disassemble the 


\section{Table 4. Inventory of a PDP Boxed Waste Surrogate}

1. One SWB matrix surrogate box housing consisting of an SWB acquired, modified, and serial numbered for the PDP

2. One set of 24 source insert fixtures, each with source height locating pins

3. One set of 60 SWB matrix inserts and associated matrix spacers for metals waste

4. One set of 60 SWB matrix inserts and associated matrix spacers for combustibles waste

5. One set of $20 \mathrm{SWB}$ matrix inserts for zero matrix volumes ${ }^{\mathrm{a}}$

6. Transportation and storage boxes (2) for matrix insert storage ${ }^{b}$

Notes: a. These matrix inserts will be used to simulate voids in the waste matrix and to position and support the source insert fixtures when performing tests of the noninterfering matrix, i.e., a nominally empty SWB.

b. These boxes will be used for shipping the matrix inserts and for storing unused matrix inserts.

The storage container area for the PDP standards must be secured for the duration of any PDP test cycle. The SPT will coordinate with the site safeguards staff to comply with all site SNM requirements. The SPT assigned by the measurement facility will be available to inspect, inventory, and secure the standards, as well as to inspect the components of the boxed waste surrogates for defects or damage during shipping. Appropriate arrangements will be made, before shipment, with safeguards and radiation safety organizations of each participant.

The NDA PDP coordinator will provide the suppliers of standards and boxed waste surrogates with the necessary contact information (names, phone numbers, and addresses) for each participating site. The respective suppliers will notify each site contact at least 2 weeks before the proposed shipping date for PDP standards and boxed waste surrogates. The PDP standards will be sent to the address and individual designated by the facility. The contact at each site shall notify the NDA PDP coordinator in writing (with a copy to CBFO) of any changes to the contact information at least 2 weeks before the scheduled shipping date. Such notification must include a statement that the new designated individual is authorized by the site to receive and handle the radioactive standards for the program. Evidence of QA training and other minimum qualifications discussed in section 4 of this document must also be presented. 


\subsection{PDP Sample Components Receipt}

Immediately on receipt of PDP standards and/or boxed waste surrogates, the SPT shall locate the shipping manifest.

The SPT shall verify that the standards and components of the boxed waste surrogates actually received match those listed on the shipping manifest both by serial number and physical description. The SPT shall verify that components have not been damaged during shipping.

1. If there is a discrepancy, the SPT shall notify the NDA PDP coordinator immediately and await further instructions.

2. If there are no discrepancies, the SPT shall indicate receipt by signing any required shipping manifests or return receipts at the appropriate locations.

The SPT shall

- Distribute copies of the signed shipping manifest and/or return receipts as required by internal procedures and instructions received from the shipper.

- Ensure that all components are securely stored in the designated area.

- Maintain security on all PDP standards and ensure that PDP standards are used only in accordance with the written policy of CBFO. All questions about permissible use shall be referred to the $\mathrm{CBFO}$ or the NDA PDP coordinator.

- Ensure that all PDP standards are handled and stored in full compliance with all site requirements. 


\subsection{TEST BOXES}

\subsection{Responsibilities}

A two-person SPT, consisting of a PDP standards custodian and a PDP standards configuration attestant, shall be assigned by each measurement facility. When selecting SPT members, the measurement facility must ensure that candidates, at a minimum, possess the following qualifications and experience:

1. Full-time employee of the measurement facility.

2. Independent of the measurement group being tested; that is, neither member of the SPT may participate in assay measurements of PDP samples that they have helped prepare.

3. QA trained, including site QA training and the training provided by the program coordinator for SPT's.

4. Qualified to handle radioactive materials (PDP standards custodian only).

The PDP standards custodian, as the lead member of the SPT, is responsible for coordinating onsite activities with safeguard organizations, radiation safety, and PDP measurement facility contacts. These activities include, but are not limited to, PDP standard receipt, storage and retrieval of standards, inspection of stored materials (e.g., PDP boxed waste surrogates), PDP sample preparation, and PDP standard removal. During the conduct of a PDP cycle, the PDP standards custodian serves as the primary on-site point of contact for the NDA PDP coordinator and is responsible for documentation control and problem reporting.

The PDP standards configuration attestant is responsible for verifying the proper emplacement of PDP standards and matrix modules and performing security-related procedures with the samples. The PDP standards configuration attestant ensures that all operations executed by the PDP standards custodian are performed in accordance with the applicable standard preparation procedure. To perform these functions, the PDP standards configuration attestant witnesses the loading and unloading of all PDP standards and matrix modules and seals the loaded PDP sample boxes using the serialized, PDP tamper-indicating devices (TID's) provided by the NDA PDP coordinator. The PDP standards configuration attestant inspects sample boxes (a) for tampering before any measurement, (b) during the distribution cycle by random spot-checking, and (c) before PDP standard unloading. Other than the SPT, no observers of the PDP sample preparation process are permitted without the prior permission of the NDA PDP coordinator. 


\subsection{Instructions for PDP Sample Preparation}

At least 2 weeks before the scheduled start date for each PDP cycle, the NDA PDP coordinator shall forward a letter of instruction to each SPT. This letter of instruction shall specify the locations and identification of each PDP standard to be inserted in each boxed waste surrogate to be used in that cycle. This information is supplied on two forms (see appendix F). A PDP Matrix Configuration Form for SWB (one for each tier) identifies the locations in the surrogate housing for specific waste matrix inserts. A PDP Standard Configuration Form for SWB identifies the locations in the assembled matrix configuration for specific radioactive standards.

1. The PDP standards custodian shall identify the matrix inserts using the applicable sample preparation procedures provided by the NDA PDP coordinator. The sample preparation procedures provide the SPT with specifications for loading of the matrix inserts into the boxed waste surrogates. The PDP standards configuration attestant shall verify that the proper matrix inserts were selected for placement in the PDP boxed waste surrogate housing.

2. The PDP standards custodian shall identify the correct standards using the applicable sample preparation procedures provided by the NDA PDP coordinator. The sample preparation procedures provide the SPT with specifications for loading of the standards into the boxed waste surrogates containing the assembled matrix configuration. The PDP standards configuration attestant shall verify that the proper standards were selected for placement in the assembled PDP sample matrix configuration.

3. The SPT shall coordinate the placement of PDP matrix surrogate box housing, matrix inserts, and PDP sample standards into a designated sample preparation area.

4. The PDP standards custodian shall examine all required PDP sample components (i.e., box housing, matrix inserts, and PDP standards) using the site-specific sample preparation procedure. The objective of the pre-load examination is to determine if any components are missing or damaged.

If there is a damaged or missing PDP sample component, the SPT shall take appropriate action depending on the component missing or damaged.

a) If the component is an expendable item (e.g., a TID or form), the SPT shall determine if a spare component can be retrieved from on-site inventory. If the SPT has a spare component in inventory, the missing or damaged item is replaced with the spare.

b) If a spare component is not available in inventory or if the missing or damaged item is one of the radioactive standards, a matrix insert, or a part of a matrix surrogate housing, the PDP standards custodian will immediately notify the NDA PDP coordinator. The SPT shall secure all materials and await further instructions. 
5. The PDP standards custodian shall insert each matrix insert into the identified position of the matrix surrogate housing, as delineated in the site-specific sample preparation procedure. Insert positioning shall be independently verified to be correct and documented.

6. The PDP standards custodian shall insert the designated standard(s) into the identified position(s) of each of the 24 source insert fixtures, as delineated in the site-specific sample preparation procedure. When the standards have been inserted into an insert fixture, the PDP standards custodian shall insert that insert fixture into the designated position in the assembled matrix surrogate before loading the next insert fixture. Source and fixture positioning shall be independently verified to be correct and documented.

7. Once all standards have been positioned and the placement verified, the PDP standards configuration attestant shall close the surrogate housing lid and seal the PDP sample with the appropriate serialized TID's.

8. The PDP standards custodian shall seal the envelope containing a copy of the PDP Standard Configuration Form for SWB (see appendix F) with a tamper-indicating security seal and affix it to the top of the sample housing. This copy of the PDP Standard Configuration Form for SWB provides relevant standard information, including standard activities and standard locations within the PDP sample. It may be opened only during an emergency or at sample disassembly. If the security seal for the PDP Standard Configuration Form for SWB is broken before PDP sample disassembly, all analysis data for that sample will be considered invalid. A site-specific form may be used in place of this copy of the PDP Standard Configuration Form for SWB if the site staff responsible for tracking and accounting of SNM requires a specific form.

9. The PDP standards custodian shall prepare a PDP Sample Custody Form for Nondestructive Assay (custody form, see appendix F) for sample acceptance by the measurement facility.

Steps 1-9 are repeated for each PDP sample preparation.

The PDP standards custodian shall return any unused materials to storage and secure the PDP standards storage area with a TID. A site-specific security system may be used in place of the supplied TID as long as the prevention of unauthorized access to the unused standards by the staff responsible for the PDP assays can be ensured and documented.

The PDP standards custodian shall transfer the PDP samples and custody forms to the assay coordinator and obtain his/her receipt signature for each prepared PDP sample.

After the assay coordinator's signature is obtained on each custody form, the following materials must be returned to the NDA PDP coordinator (or designee): 
- The originals of the PDP sample configuration forms

- One copy of each PDP custody form

If multiple assay systems are to be qualified at one site, it will be the assay coordinator's responsibility to coordinate schedules and transfers between the various assay systems at the site. If there is insufficient time to make all measurements for the number of assay systems planned for participation, the assay coordinator should request an extension pursuant to section 5.2.

The SPT shall maintain all records of PDP sample preparation in strict confidence until CBFO distributes a final report or the NDA PDP coordinator otherwise indicates that the data for the cycle have been released. 


\subsection{ANALYTICAL AND DATA REPORTING REQUIREMENTS}

This section describes activities required of participating measurement facilities for PDP sample acceptance, analysis, and reporting.

\subsection{Simulated Waste Container Acceptance}

The participating measurement facility shall designate a measurement group point of contact, referred to as the assay coordinator, who is responsible for accepting PDP simulated waste containers and ensuring that chain-of-custody protocols are followed.

On initial receipt the assay coordinator shall inspect the condition of the housing seals by checking the TID's on each PDP sample to ensure that they are intact. If a problem exists with the integrity of any TID's, the PDP sample should be rejected and returned to the SPT. The assay coordinator shall confirm the accuracy of each custody form.

If TID's are intact and all data are in order, the assay coordinator shall review, sign, and date each custody form. This custodial signature means that the measurement facility accepts the PDP simulated waste container. The date of signature establishes the validated date and time of sample receipt (VTSR). At this point the SPT pulls two copies of each custody form, retaining one copy and returning the other copy to the NDA PDP coordinator.

All subsequent transfers of the PDP samples within the measurement group and ultimate return of the PDP samples to the SPT will be documented on the PDP sample custody form accompanying the PDP sample.

\subsection{Analysis}

The measurement facility shall analyze the contents of each PDP simulated waste container six times using the procedures that are planned for use in the WIPP waste characterization program. These procedures must have been internally demonstrated to meet the QAO's and must have been approved within the site-specific system for control of operating procedures. The PDP simulated waste container must be completely removed from and replaced into the assay system between sequential measurements.

Analyses should be completed and reported as soon as possible, but in any case must be forwarded to the NDA PDP coordinator within 28 days after the VTSR, except as noted below. The signature date by the assay coordinator on the PDP Sample Custody Form for Nondestructive Assay represents the VTSR and should be considered day 0 when calculating calendar days to determine the reporting due date.

If a participant's analyses will not be reported by the due date and the participant desires an extension, the participant must notify the NDA PDP coordinator in writing (e-mail, fax, etc.) as soon as possible and request an extension. The NDA PDP coordinator will forward the request with a recommendation to the $\mathrm{CBFO}$. The request will be either granted or rejected in writing by 
the CBFO. All extensions must be requested and granted before the due date. If an extension has not been granted prior to the due date, the NDA PDP coordinator may make the actual identity and concentrations of the analytes in the PDP samples known at any time thereafter. Any participant who had not yet reported will then not be able to use these data to qualify for analysis of WIPP samples.

\subsection{Reporting}

The participating measurement facilities shall send a summary of all isotopes listed in table 1 for which assay method approval is sought, for all replicate analyses, to the NDA PDP coordinator. The activities of detected isotopes must be reported irrespective of the relationships of those activities to detection limits quoted or demonstrated for the program. The following specifications apply to the summary report:

- Reports shall be forwarded directly to the NDA PDP coordinator. Express mail or overnight delivery service is preferred, but in any case all analytical reports to the NDA PDP coordinator shall be postmarked or shipped no later than 28 calendar days after the VTSR (except as noted in section 5.2).

- Analytical reports shall be submitted for each PDP sample. Reports are required in hard copy and in a prescribed computer-readable format.

\subsubsection{Report Contents}

Reports shall consist of at least the following information for each determination:

a) Identification of the reporting measurement facility, including the new system ID obtained from the registration process

b) Identification of the PDP cycle and program component for which the data are being reported

c) Identity of the PDP sample by the identification number from the PDP Sample Custody Form for Nondestructive Assay

d) Any additional identification assigned to the PDP sample by the measurement facility

e) Identification of the instrument system and method (including revision number) used for each isotope (sites using a set of constant isotope ratios shall so indicate on the report form)

f) Identification of the replicate number corresponding to the analytical data

g) Identity and activity in curies for each target isotope identified

h) Counting uncertainty and estimated total uncertainty for each identified isotope

i) Total ${ }^{239} \mathrm{Pu}$ fissile gram equivalents (g) and associated total uncertainty

j) Total alpha activity and associated total uncertainty (curies) 

k) Thermal power and associated uncertainty (W)
1) Elapsed counting time
m) Date and time of NDA

The results of each individual analysis must be reported, not the average of the six determinations. The form in appendix F, Performance Demonstration Program Report Form Nondestructive Assay, or a reasonable facsimile, should be used to report the data to the NDA PDP coordinator. Continuation sheets may be used if the comments of the measurement facility exceed the allocated space on the report form.

A computer-readable electronic copy of the reporting data for all PDP samples must be provided by the measurement facility on a diskette or by direct transmission. All participants in the NDA PDP are provided with a copy of an electronic data recorder (EDR). The EDR is a tool for generating the electronic deliverable in the correct format and will also print a copy of the report. Regardless of the method of transmission of the EDR-generated files, signed hard copies of the report forms must also be provided for the QA records.

Corrections to data will be accepted if received in writing before the scoring report is completed. Data may also be corrected by fax if followed by express mail or overnight courier transmission of the original hard copy and the electronic deliverables disk. Verbal corrections to data will not be accepted. The reports shall be signed by a measurement facility staff member assigned this responsibility. Reports shall contain an explanation for the change and any other information deemed relevant by the measurement facility.

\subsubsection{Analytical Records}

The requirement to submit only summary data for scoring does not relieve the measurement facility from the requirement to maintain appropriate assay records and documentation. The records generated during the assay of the PDP samples are QA records. They must be maintained in a traceable and auditable condition. Storage conditions and duration must meet the requirements of the QAPD and other implementing QA documents and procedures.

\subsection{Completion and Disassembly}

After the measurements are complete and the PDP samples are returned from the assay coordinator, the SPT is authorized to disassemble the PDP samples at the site's convenience. 
The PDP samples shall be disassembled by the following procedure:

1) The PDP standards custodian shall retrieve the appropriate PDP Sample Custody Form for Nondestructive Assay, the PDP configuration forms (matrix and standard) for the PDP sample to be disassembled, and a new PDP Sample Disassembly Form for Nondestructive Assay of SWB (disassembly form; appendix F). If more than 10 standards were used in the test configuration, multiple disassembly forms may be used. Number the standards on the second page, standards 11 through 20, and so forth.

2) The PDP standards custodian shall determine the condition of the security seal on the PDP configuration forms (see appendix F) on the top of the sample housing. The condition shall be noted on the PDP disassembly form. If the seal is not already broken, the PDP standards custodian breaks the security seal and removes the PDP configuration forms from the top of the sample housing. If the security seal for the PDP configuration forms is broken before PDP sample disassembly, all analysis data for that sample will be considered invalid.

3) The PDP standards custodian shall determine the condition of the TID's on the sample housing lid. The condition shall be noted on the PDP disassembly form. If the TID's are not already broken, the PDP standards custodian breaks the TID's and removes the sample housing lid, allowing the fixtures containing the PDP standards to be removed. If any of the TID's are broken before PDP sample disassembly, all analysis data for that sample will be considered invalid, and the PDP standards custodian shall notify the NDA PDP coordinator.

4) The PDP standards custodian removes each of the standards from their positions in the source insert fixtures. Each team member shall independently verify that each source positioning is correct against the PDP standard configuration form.

5) After removal of the standards, each team member shall verify the correct placement of each matrix module for each tier and document their observations on the disassembly form.

6) If there is a damaged, missing, or misplaced PDP sample component, this information must be recorded on the PDP disassembly form.

7) Once all standards have been removed and the placement verified, the standards custodian will coordinate the return of the PDP sample housing, matrix inserts, and the PDP sample standards to the designated, secured storage area under the facility's normal storage procedures.

8) The disassembly operations shall be documented on the PDP sample custody form under "Disposition."

9) The PDP standards custodian shall return the completed originals of the custody form and the disassembly form immediately to the NDA PDP coordinator. If any TID, custody seal, sample housing, matrix insert, or standard shows evidence of tampering, the PDP standards custodian shall ensure that the evidence of tampering is secured and that the condition is noted on the forms. The PDP standards custodian shall then immediately notify the NDA PDP coordinator and await further instruction. 


\subsection{EVALUATION OF PERFORMANCE DATA}

The scoring system for the PDP is pass-fail. In order to pass a specific test, the measurement must fall within the specified test criteria for the PDP (see table 3). In order to pass the PDP cycle, the measurement assay system must pass all individual tests.

NDA performance is evaluated in the areas of precision and bias. Precision is defined in this context to mean the relative standard deviation calculated from several replicate measurements of the identical PDP sample under fixed conditions. Bias is the systematic error component of the total uncertainty. Instrument bias is taken to mean the bias of a particular instrument under essentially ideal conditions as practically as can be obtained. This bias is specific to the instrument in isolation from interfering effects such as matrix and source distribution effects. Instrument bias is estimated for the noninterfering samples by determining the measurement accuracy of a series of replicate measurements. It is intended as a baseline determination and control on the instrument itself, independent of complicating measurement conditions.

Total accuracy is defined as the closeness of the mean results obtained from a measurement system to the known or accepted reference or standard values. In this program total accuracy is estimated from the measurement results for PDP samples that include sources of variance in addition to those measured in the zero matrix configuration. Additional variance sources include matrix variations, isotopic compositions, spatial distributions, contaminating radionuclides, and other interfering effects. The determination of an average total accuracy is used as an estimate of bias for interfering matrices.

Total uncertainty is the total measurement error from all variance sources. This definition includes sources of error that will not be testable within the limitations of the PDP.

Both precision and bias are measured for all PDP samples. Different criteria have been established in the noninterfering and interfering matrices. Precision and bias for the noninterfering matrix are determined from measurements on the zero matrix configuration. Precision and bias determinations for all simulated waste matrices are compared to the criteria for interfering matrices.

The basis for the scoring system of the PDP is to ensure that the QAO's for precision and bias are satisfied at the 95 percent confidence level and for a reasonable number of replicate samples. A reasonable number of samples is defined as six replicate samples in this instance. This number of determinations permits an adequate statistical evaluation without overburdening the measurement participants with excessive replicate measurements. 


\subsection{Scoring System}

Because NDA involves an inherently probabilistic process, the specification of a scoring system to demonstrate compliance with the QAO's must be based on probabilistic confidence intervals. The underlying distribution of any NDA measurement is assumed to be normal. However, the variance of this normal distribution, which is the true precision of the NDA instrument, is $a$ priori unknown, and is one of the performance parameters that is measured by the PDP.

The instrument precision is equal to the standard deviation of the underlying measurement distribution. It is measured by making several replicate measurements on a single known PDP sample. The measured standard deviation is generally not identical to the underlying distribution standard deviation, but the two are related by the chi-square distribution. Similarly, the measured or the sampled mean will be related to the mean of the underlying distribution by the Student's $t$-distribution, because the underlying variance is not known. Because only six determinations are required in the PDP, the numerical criteria for both the precision and the bias are adjusted to ensure the same level of confidence that the theoretical QAO's are demonstrated in each case.

Precision is expressed as the measured percent relative standard deviation (\%RSD) for the sample. Relative precision values used in the PDP are calculated relative to the reference (or known) value for the PDP sample. This permits the test of precision to be equitable among the sites and independent of the measurement bias. Referencing the relative standard deviation to the known value also preserves the assumption of the chi-square definition integral to the statistical arguments in appendix C. For the NDA Box PDP the \%RSD is determined using equation 1.

$$
\% \operatorname{RSD}=100 \times \frac{\sqrt{\frac{\sum_{i=1}^{n}\left(x_{i}-\bar{x}\right)^{2}}{n-1}}}{\mu_{0}}
$$

where:

$$
\begin{array}{lll}
x_{i} & = & \text { sample value } \\
\mathrm{n} & = & \text { the number of measurements } \\
\mu_{0} & = & \text { actual known PDP sample value } \\
\bar{x} & = & \text { the average sample value, defined by } \\
\bar{x}=\frac{\sum_{i=1}^{n} x_{i}}{n} &
\end{array}
$$

A chi-square distribution is assumed for the evaluation of precision. To evaluate the bias in the mean or the total accuracy, a Student's $t$-distribution is assumed. Two parameters need to be specified: the required confidence limit and the required number of replicate samples (also known as the degrees of freedom plus one).

Compliance with the QAO's requires demonstration at the 95 percent confidence level, consistent with the WAC and other sections of the PDP. 
The degrees of freedom were selected to be five (i.e., six replicate measurements). The number of replicates determines the width of the chi-square and Student's $t$-distributions. As the number of replicate samples increases, the widths of the distributions decrease. However, for large numbers of replicate samples the improvement diminishes. Six replicates were selected as a compromise between maintaining a reasonable number of samples and using any larger numbers to reduce the width of the distribution gradually. The required measured precision for the noninterfering matrix was then calculated from the assumption that the PDP precision criteria represent the 95 percent upper confidence bounds of a chi-squared distribution, at five degrees of freedom. Column 4 of table 3 shows the required measurement precision obtained from these calculations. The limits in column 5 of table 3 were modified further based on the additional sources of uncertainties in the interfering matrices.

For the bias measurements, the upper and lower 95 percent confidence limits for the two-sided Student's $t$-distribution were used to modify the limits in columns 6 and 7 of table 3 . For scoring purposes, the bias limits in table 3 are reduced by the half-width of the 95 percent confidence bound of the Student's $t$-distribution. Assuming six replicate samples and a 95 percent confidence level, this equation can be expressed as

$$
\left(\% \mathrm{R}_{\mathrm{L}}+1.05 \times \% \mathrm{RSD}\right) \leq 100 \times \frac{\overline{\mathrm{x}}}{\mu_{\mathrm{o}}} \leq\left(\% \mathrm{R}_{\mathrm{H}}-1.05 \times \% \mathrm{RSD}\right) .
$$

where:

$$
\begin{array}{lll}
\% R_{L} & =\quad \begin{array}{l}
\text { low } \% \text { recovery limit specified in table } 3, \text { column } 6 \text { or } 7 \\
\text { (noninterfering or interfering), as appropriate }
\end{array} \\
\% R_{H} & =\quad \begin{array}{l}
\text { high } \% \text { recovery limit specified in table } 3, \text { column } 6 \text { or } 7 \\
\text { (noninterfering or interfering), as appropriate }
\end{array}
\end{array}
$$

Other terms are as indicated above. This condition requires that

$$
1.05 \times \% R S D \leq\left|100-\% R_{L, H}\right|
$$

Otherwise, the test will fail.

Appendix $\mathrm{C}$ discusses the statistical bases for the scoring criteria in detail.

\subsubsection{Bias of Quantitation of Simulated TRU Wastes}

Purpose: NDA results for replicate analyses for PDP samples of known alpha activity are used to determine the bias with which a measurement facility can quantitate the total alpha activity. Bias is estimated from a determination of the total accuracy of a measurement. The total accuracy is the closeness of the mean results obtained from a measurement system to the known or accepted reference or standard values. In this program total accuracy is determined from the measurement results for PDP samples that 
include variance and bias elements in addition to those associated with the zero matrix configuration, including effects due to sample matrix and isotope characteristics.

Criteria: The results reported for total alpha activity shall not deviate from the reference value, $\mu_{\mathrm{o}}$ (true sample value), by more than the amount specified in equation 3 using the values for $\%$ R specified in column 7 of table 3 (bias for an interfering matrix). The selection of the appropriate criteria specified in table 3 is based on the known total alpha activity range in which the prepared PDP sample falls.

Method: The bias of quantitation shall be computed by measuring six replicate samples and calculating the mean, $\bar{x}$ (equation 2) and the percent relative standard deviation, $\% \operatorname{RSD}$ (equation 1). The measurement will pass this criterion if equation 3 is satisfied and will fail if equation 3 is not satisfied. The values for $\% \mathrm{R}$ in equation 3 are the low and high values specified in the total bias column of table 3 that corresponds to the total alpha activity range in which the prepared PDP sample falls.

Actions: For PDP samples for which the total bias is outside the limits established in table 3 for the activity range tested, the measurement facility will be judged as unable to quantitate for that specific activity range. The impact of exceeding an action level on overall measurement facility performance is given in section 6.1.4. In accordance with section 7 , the site project manager is responsible for ensuring that appropriate corrective actions are taken when necessary.

\subsubsection{Instrument Bias}

Purpose: NDA results for replicate analyses for PDP samples of known activity in a zero matrix configuration containing known source isotopics are used to determine the instrument bias with which a measurement facility can measure the total alpha activity. In this particular instance, the instrument bias is estimated from the total accuracy determined for a noninterfering sample.

Criteria: The results reported for total alpha activity shall not deviate from the reference value, $\mu_{\mathrm{o}}$ (true sample value), by more than the amount specified in equation 3 using the values for $\% \mathrm{R}$ specified in column 6 of table 3 (bias for a noninterfering matrix). The selection of the appropriate criteria specified in table 3 is based on the known total alpha activity range in which the prepared PDP sample falls.

Method: The method for determining the instrument bias shall be identical to the method for the bias of quantitation of simulated TRU wastes (section 6.1.1), except that the reference values used from table 3 will be from the noninterfering bias column. Also, the bias determination will be done only on PDP samples assembled from the zero matrix configuration. 
Actions: The actions for the instrument bias determination are identical to the actions for the determination of the bias of quantitation of simulated TRU wastes (section 6.1.1).

\subsubsection{Precision of Replicate Determinations}

Purpose: To demonstrate compliance with the QAO's for precision by replicate processing, NDA results from replicate analyses of a PDP sample of known alpha activity are used to determine the precision with which a measurement facility can quantitate total alpha activity.

Criteria: The results reported for total alpha activity from replicate measurements of an identical sample shall not exhibit a measured relative standard deviation greater than that specified in table 3 , column 4 for the zero matrix configuration and column 5 for all other simulated waste matrices.

Method: The analytical results from the six replicate measurements of an identical sample are used to calculate the relative standard deviation using equation 1 . The measured standard deviation is then compared with the values listed in table 3 . For the zero matrix configuration, if the measured value is less than that specified in table 3 , column 4 , the measurement passes this test. For all other simulated waste matrices, if the measured value is less than that specified in table 3 , column 5 , the measurement passes this test.

Actions: For any sample for which results exceed the appropriate $\mathrm{QAO}$ for precision in any sample activity range (see table 3 ), the measurement facility will be judged as unable to quantitate for that specific alpha activity range. The impact of exceeding an action level on overall measurement facility performance is given in section 6.1.4. In accordance with section 7 , the site project manager is responsible for ensuring that appropriate corrective actions are taken when necessary.

\subsubsection{Overall Performance}

Purpose: Measurement facility performance on the entire set of PDP samples is used to assess general problems that may affect the measurement facility's ability to analyze total alpha activity within an SWB. This conclusion could result in a holding period during which the measurement facility would not use the assay data from the affected system to certify wastes for WIPP until the causes of the problems are identified, corrective action is taken, and the efficacy of the corrective action is demonstrated.

Criteria: The criterion used to evaluate overall measurement facility performance is as follows: Measurement facilities must pass all performance criteria for an activity range demonstrated by this program to be considered qualified to perform NDA on WIPP samples for that activity range tested.

Method: The NDA results for the PDP samples must meet all of the criteria identified in sections 6.1.1, 6.1.2, and 6.1.3 of this PDP Plan. 
PDP Sample or Isotopic Disqualification: If the preponderance of evidence from the participating measurement facilities supports a conclusion that a PDP sample was inadequate to demonstrate compliance with the criteria of the PDP, the NDA PDP coordinator may judge the data for that PDP sample to be inappropriate for use in evaluating performance for that particular performance demonstration.

Actions: The site project manager is responsible for ensuring that appropriate corrective action measures are implemented when a measurement facility exceeds an action limit. The following are considered minimum mandatory measures that must be implemented when action limits are exceeded.

If a measurement facility fails the criteria of sections 6.1.1, 6.1.2, or 6.1.3 applicable to a given cycle, the measurement facility will be judged to have exceeded an action level.

Any measurement facility that has exceeded an action level shall discontinue the use of any potentially affected assay data for certification of WIPP wastes. The measurement facility may not use such potentially affected assay data for certification of WIPP wastes until it obtains approval from CBFO to do so. To obtain this approval, the facility must submit a report to $\mathrm{CBFO}$ containing the following items:

1. The results of an investigation of the cause of the failure(s).

2. Description of any corrective actions completed and/or proposed as a result of the investigation.

3. Supporting data sufficient to demonstrate that the same problems will not recur.

4. A plan and schedule for the disposition for all potentially affected radioassay data, for example, any data collected prior to the first PDP cycle, between a successful and a failed PDP cycle, or between completion of a PDP cycle and the issuance of the report for that cycle. (Such data shall be treated as potentially nonconforming under the facility's QA program.)

5. An assessment of the impact of the measurement facility's "Not Approved" status for NDA on waste characterization activities at the site.

6. A proposed mechanism for obtaining approved status from $\mathrm{CBFO}$, including a request for approval in a supplemental PDP cycle or for approval with waiver of a supplemental cycle.

NOTE: Due to the limited nature of the tests within a PDP cycle, any failure must be assessed thoroughly to determine the extent of impact on a site's TRU waste characterization program. In many cases, the failure involves the ability of an assay system to measure one or a limited number of similar waste streams. Alternatively, depending upon the specific nature of the test and/or failure(s) that occurred, the failure(s) 
could indicate a broader system problem affecting all measurements made by the system. Such issues must be addressed and documented by a site when identifying any "potentially affected assay data" following a PDP failure.

For example, assume a PDP cycle involved testing of a simulated heterogeneous (debris) waste and a simulated metals, and that a system received a passing score for debris while failing on the metals. In such a case, "affected assay data" would only involve any generated for metals (or similar) type wastes; debris and similar waste data would continue to be acceptable for TRU waste characterization purposes.

The CBFO may elect to grant conditional approval for a measurement facility to use potentially affected radioassay data or to generate new waste characterization data for this program if such conditional approval will not compromise the overall quality of the data being generated for the program. Such conditional approvals will be granted with appropriate limitations and conditions to guarantee that suspect data will not be used in the program.

Prior to granting approval to the facility to use the potentially affected radioassay data and/or to continue to generate new waste characterization data for certification of WIPP wastes, $\mathrm{CBFO}$ may require that the measurement facility demonstrate adequate performance, that is, meet the scoring criteria described in 6.1.4 on another set of PDP samples. If this requirement is invoked, CBFO may direct that a supplemental cycle be conducted or that approval be withheld pending participation in the next regularly scheduled cycle of the PDP. CBFO may elect not to invoke this requirement if:

a) The measurement facility can prove that the cause of its failure to meet performance criteria resulted purely from calculational errors (including incorrect or inappropriate software algorithms or assumptions) and that appropriate control measures have been initiated to prevent recurrence of the errors; or

b) CBFO concludes that such a waiver represents acceptable risk to the integrity of program data.

Section 7.3 discusses the circumstances that will be considered by CBFO in determining the need and schedule for supplemental cycles to the NDA Box PDP. 


\subsection{REPORTING OF PERFORMANCE DATA}

\subsection{Summary of Data}

The NDA PDP coordinator shall review and evaluate the results, compile them into a master summary, and deliver this summary to the CBFO within approximately five weeks after the receipt of the last measurement facility data set. The report summary shall include the values reported by the measurement facilities, the reference isotopic values, the acceptance ranges, and the pass or fail status of each individual measurement facility.

The CBFO, in conjunction with the NDA PDP coordinator and PDP manager, will evaluate individual measurement facility performance and approve individual measurement systems for participation in the WIPP waste characterization program. At any time in the evaluation process, $\mathrm{CBFO}$ may request additional information from or hold discussions with participants with respect to the systems and procedures used to measure calibration, performance check samples, PDP samples, and/or actual wastes. As a result of the PDP performance and related evaluations CBFO may issue unqualified approvals, may disapprove a method, may issue approvals limited to specific activity or weight ranges or waste types, or may make approvals conditional on other required actions. The generator site project manager(s) shall be responsible for ensuring that appropriate corrective action measures are taken and that all conditions and limits on method approvals are met.

\subsection{Distribution of Reports}

Copies of the summary report are distributed to each of the DOE Operations Offices involved, each of the participating measurement facilities, and other individuals and organizations deemed appropriate by the CBFO. The CBFO shall also provide written notification to the DOE Operations Offices regarding the adequacy and approval status of their participating measurement facilities.

\subsection{Backup PDP Samples}

A backup set of PDP simulated waste containers can be prepared by the SPT approximately 4 weeks after measurement facilities are notified of their status. Measurement facilities that do not pass on the initial test may request to have these samples prepared at their facility. Requests must be submitted in writing to the $\mathrm{CBFO}$ and be accompanied by the report required in section 6.1.4. If CBFO authorizes a supplemental cycle, the schedule of cycle initiation, analysis, scoring, and approval/disapproval actions by CBFO will be negotiated for each supplemental cycle. The schedule will be based on a review of impacts on the overall WIPP schedule and program costs and may include discussions with the potential participants. Timing and selection of measurement facilities for participation in supplemental cycles will be entirely at the discretion of the CBFO. Primary consideration will be given to preventing adverse impacts on WIPP waste characterization and compliance schedules.

\subsection{Measurement Facility Status}


Once the CBFO has determined measurement facility status as "approved" with respect to analyses that are required to demonstrate compliance with regulatory requirements, such status shall remain in effect for a maximum of 13 months (i.e., 12 months plus a one-month "grace" period). All measurement facilities must participate in the annual primary cycle in order to remain qualified to perform WIPP analyses. A timely response in the annual primary cycle will ensure that a measurement facility will not exceed its qualification time limit. Measurement facilities obtaining approved status through a supplemental distribution cycle must participate in the next regular distribution cycle to maintain their approved status. Treatment of radioassay data by facilities undergoing a change in status is discussed in section 6.1.4.

The qualification period for a measurement facility begins with the date that analyses in a PDP cycle are completed. At the end of the 13th month, a facility that has not yet successfully completed their analyses of PDP samples to requalify their method may choose to proceed at risk with WIPP analyses or cease operations. The facility should recognize that data obtained at risk may be found to be unacceptable to WIPP. Data generated at risk cannot be used for characterizing waste for shipment to WIPP until:

- The system used to collect the data passes the PDP, and

- The data have been reconciled through the dispositioning of a nonconformance report.

\subsection{Quality Assurance Records}

The minimum QA records for the NDA Box PDP are identified and listed below in accordance with the QAPD requirements. In addition, the NDA PDP coordinator may determine that records of other program activities are QA records and enter them into the QA records system with the same level of control and maintenance.

These QA records may be organized by NDA PDP Plan revision, by PDP cycle, or other principle, as applicable. These records are nonpermanent records and shall be maintained in accordance with the QAPD requirements. Records disposition, when applicable, will be in accordance with $\mathrm{CBFO}$ /NTWCT requirements and approved procedures and Work Plans.

All QA records identified in this plan shall be stored in accordance with record storage requirements in the QAPD. Access to QA records will be limited to personnel involved in the program or having related QA or records custodial responsibilities.

QA records for the NDA Box PDP include the following:

- Work Plans (all revisions)

- PDP Plans (all revisions)

- Procurement records

- Radioactive standard and matrix surrogate design and production records

- $\quad$ SPT training

Training materials, attendance records 
- Assay system registration forms

- Records of cycle set up (each cycle)

Notification letters, shipping records, other correspondence

- Participant's assay reports and supporting forms (each cycle)

Assay data report forms, chain-of-custody records, configuration forms, disassembly forms

- Scoring reports (each cycle) and CBFO cover memo

- Reviews of corrective actions and supporting data and recommendations made to CBFO (each cycle)

- Software documentation for QA-related programs written for the NDA Box PDP, as defined in the applicable, approved software procedure (each version, each program). SPT training CD, EDR 


\section{GLOSSARY}

ACCURACY - The degree of agreement between a measured value and an accepted reference of the true value. Accuracy is determined as the percent recovery $(\% \mathrm{R})$.

ACTIVE SYSTEM - An operational NDA system currently located at a participant site and qualified to perform waste characterization activities at that site. This includes systems that are not actively assaying waste because of scheduling issues or other extraneous site issues not connected to system capability or readiness.

ASSAY COORDINATOR - Facility point-of-contact responsible for accepting PDP samples and ensuring that chain-of-custody protocols are followed.

BIAS - The systematic error component of the total uncertainty, that is, a constant positive or negative deviation of the method average from the correct value or an accepted reference value under specific measurement conditions.

CORRECTIVE ACTION - Measures taken to rectify conditions adverse to quality and, where necessary, to preclude their recurrence.

INACTIVE SYSTEM - An operational NDA system not currently proposed or scheduled (if site-owned) or deployed under contract (if commercially owned) to perform waste characterization activities at a site.

INSTRUMENT BIAS - The bias of a particular instrument (or measurement system) under essentially ideal conditions, that is, when all sample-specific or matrix effects have been reduced to their practical minima. In this program the instrument bias will be approximated by the accuracy of the measurement for samples with the zero matrix or a benign matrix.

MATRIX INSERT - A designed and manufactured modular insert that will simulate an expected waste matrix condition. Three tiers of 20 inserts are required to completely fill the SWB's used to prepare PDP samples for the NDA Box PDP. Sixteen of the 20 inserts are sixsided rectangular boxes; four are five-sided cutouts from a right circular cylinder with one surface curved to conform to the rounded end of a standard waste box. A zero matrix insert is one containing only the support for insertable standards.

NDA PDP COORDINATOR - An individual responsible for coordinating the technical operations of the NDA PDP, including PDP sample component preparation, SPT oversight, scheduling, scoring, and report summary generation.

NONDESTRUCTIVE ASSAY (NDA) - Assay methods for waste items that do not affect the physical or chemical form of the material. 
OUT-OF-SERVICE SYSTEM - A previously approved NDA system that is not currently performing waste characterization activities at a site due to malfunction or voluntary shutdown for maintenance, repairs, upgrading, or recalibration.

PDP MANAGER - An individual responsible for overall performance of, and coordination among, the three PDP's (HSG, RCRA, and NDA).

PDP SAMPLE - A blind sample prepared and sealed by the SPT for subsequent analysis by a measurement facility for qualification under the PDP. A PDP sample for the NDA Box PDP is composed of a modified standard waste box, inserts simulating specific waste configurations, and insertable PDP standards.

PDP STANDARD - A radioactive source specifically prepared or acquired and certified for the PDP.

PDP STANDARDS CONFIGURATION ATTESTANT - A member of the two-person SPT responsible for verifying the proper emplacement of PDP sample standards and performing sample security-related procedures.

PDP STANDARDS CUSTODIAN - The lead member of the SPT responsible for coordination of on-site PDP sample preparation activities.

PRECISION - A measure of the mutual agreement among individual measurements of the same property made under prescribed similar conditions; expressed as a standard deviation or percent relative standard deviation (\%RSD).

PRIMARY CYCLE - The first cycle of a primary/supplemental pair of NDA PDP cycles. Similar test configurations are maintained for the two paired tests since they are intended to provide approximately equivalent test opportunities for the participants.

PROGRAM COORDINATOR - A CBFO-designated organization that administers and coordinates PDP functions. The program coordinator will designate the PDP manager.

SAMPLE PREPARATION PROCEDURE - A procedure generated by the NDA PDP coordinator for each PDP cycle. This procedure provides instructions to the SPT on PDP standard placement and matrix identification within the test box.

SAMPLE PREPARATION TEAM (SPT) - A two-person team, consisting of a PDP standards custodian and PDP standards configuration attestant, that prepares and certifies measurement facility PDP samples. The SPT is responsible for ensuring that each PDP simulated waste container is prepared according to the PDP procedures. In addition, the SPT ensures proper disassembly and return to storage of all PDP components after analysis by the measurement facility. The site designates the SPT. Training is provided and documented by the program coordinator.

STANDARD WASTE BOX - A payload container designed and manufactured in accordance 
with WIPP Engineering Specification E-1-343, authorized for use with TRUPACT-II transportation packages, that has been tested by DOE to meet DOT Specification 7A Type A requirements.

SPECIAL SUPPLEMENTAL CYCLE - A special cycle conducted with the authorization of CBFO (a) for sites that fail to participate in or fail both the primary or supplemental cycle of a pair or (b) to provide a test of a unique circumstance. Authorization of a special supplemental cycle is entirely at the CBFO's discretion.

SUPPLEMENTAL CYCLE - The second or backup cycle of a primary/supplemental pair intended to handle retests of sites that fail or are unable to participate in the primary cycle. Additional supplemental cycles may be conducted on an as-needed basis at the CBFO's direction.

TOTAL ACCURACY - The closeness of the mean results obtained from a measurement system to the known or accepted reference or standard values. In this program total accuracy is estimated from the measurement results that include sources of variance in addition to those measured in the zero matrix configurations, such as variable matrices, isotopic compositions, spatial distributions, contaminating radionuclides, and other interfering effects. It is used to estimate bias for the interfering matrices.

TOTAL UNCERTAINTY - The total measurement error from all sources of variance, including the precision, the instrument bias, and interference effects such as variable matrices, isotopic compositions, spatial distributions, contaminating radionuclides, and others.

VALIDATED TIME OF SAMPLE RECEIPT - The date on which a PDP sample is received at a measurement facility, as recorded on the custody form.

ZERO MATRIX CONFIGURATION - Specifies a matrix surrogate that contains only the supports for insertable standards. 


\section{REFERENCES}

DOE 1999a. Waste Acceptance Criteria for the Waste Isolation Pilot Plant. DOE/WIPP-069, Current Revision. Carlsbad, New Mexico, Waste Isolation Pilot Plant, U.S. Department of Energy.

DOE 1999b. Quality Assurance Program Document. CAO-94-1012, Current Revision. Carlsbad, New Mexico, Carlsbad Field Office, U.S. Department of Energy.

DOE. 2001a. Performance Demonstration Program Plan for Nondestructive Assay of Drummed Wastes for the TRU Waste Characterization Program DOE/CBFO-01-1005, Current Revision. Carlsbad, New Mexico, Carlsbad Field Office, U.S. Department of Energy.

DOE 2001b. Performance Demonstration Program Plan for RCRA Constituent Analysis of Solidified Wastes. DOE/CAO-95-1077, Current Revision. Carlsbad, New Mexico, Carlsbad Field Office, U.S. Department of Energy.

DOE 2001c. Performance Demonstration Program Plan for Analysis of Simulated Headspace Gases. DOE/CAO-95-1076, Current Revision. Carlsbad, New Mexico, Carlsbad Field Office, U.S. Department of Energy.

DOE 2001d. Performance Demonstration Program Management Plan. DOE/CBFO-01-3107, Current Revision. Carlsbad, New Mexico, Carlsbad Field Office, U.S. Department of Energy. 


\section{APPENDIX A}

\section{Criteria for Identical Assay Systems for the NDA Box PDP}




\section{APPENDIX A}

\section{Criteria for Identical Assay Systems for the NDA Box PDP}

Each manufacturer or owner/operator making a claim of identical systems shall submit a document to the NDA PDP coordinator identifying the systems and addressing each of the criteria used to define identical systems. The method performance data submitted to CBFO for identical systems must include comparisons of expected and actual performance between the systems. Procedures must be in place to ensure that the identical status of the systems is maintained and to inform $\mathrm{CBFO}$ and the affected sites immediately of any deviation from this status.

For NDA systems to be considered to be identical, the assay systems must meet all of the following criteria:

1. Each deployed system must have the same manufacturer and be identified as the same model.

2. Within each system, each quality-affecting component must have the same manufacturer and model number or be documented to have identical construction and performance specifications.

3. Each deployed system must have the same configuration, including all quality-affecting manufacturer options.

4. Each deployed system must use the same software, hardware, and procedures for calibration and operational quality control checks, including a routine intercomparison that is sufficiently detailed to demonstrate that the instruments give the same assay results (within statistical counting uncertainties) for the region (matrix/fissile mass loading) being tested by the PDP samples.

5. Each deployed system must use the same software and procedures for operation, including record keeping.

6. Each deployed system must use the same software and procedures for data reduction, review, and reporting.

7. Each deployed system must have identical qualification and performance testing criteria for the personnel operating the system or reporting data.

8. Owner/operators of each deployed system must provide the same training for all personnel operating the system or reporting data.

9. Each deployed system must be operated under the same management structure and Quality Assurance Plan. 
10. Each deployed system must use check and calibration sources with identical traceability.

11. Each deployed system must be located at the same site and have been qualified for the same function(s). 


\section{APPENDIX B}

\section{Performance Demonstration Program for NDA of Boxed Wastes NDA System Registration Form}




\section{APPENDIX B}

\section{PERFORMANCE DEMONSTRATION PROGRAM FOR NDA OF BOXED WASTES NDA SYSTEM REGISTRATION FORM}

\section{General Instructions:}

1. Registration forms are to be completed and returned to the NDA PDP coordinator at least 3 weeks prior to initial participation in the PDP.

2. All systems must be registered prior to participation in the PDP.

3. A separate registration is required for all systems, including each system in a set of identical systems.

4. After the initial submission, the forms need be resubmitted only when there is a change in the registration information.

5. The NDA PDP coordinator will acknowledge all registration requests and assign a tracking identifier to each registered system.

6. The NDA PDP coordinator will maintain a current list of all registered systems.

\section{Instructions for specific questions:}

\section{Section A}

1. Enter the full formal name of the measurement system.

2. Enter the acronym by which the system should be referred to.

3. If the system is one of a number of multiple identical systems, enter the total number of identical systems. Systems are only considered identical if the criteria in appendix A of the PDP Plan are met. If there are no identical systems, enter " 1 ".

4. Enter the number for this system to distinguish it from the other identical systems. If there are no identical systems, enter " 1 ".

5. Check the appropriate descriptor. "Fixed, Permanent" indicates that the system was intended to be installed permanently at the current location. "Transportable, Nonpermanent" indicates a long-term installation that can be relocated. "Mobile, Trailer" indicates systems intended for routine movement between sites for short-term contracts.

6. Enter the DOE site at which the system will be installed for the PDP cycle for which registration is being requested.

7. Enter the on-site location designator for the system.

8. Enter the name of the institution/facility/company that owns the system.

9. Enter the name of the institution/facility/company that operates the system.

10. Enter the name of the person who should be contacted for information on the system.

11. Enter the title of the person who should be contacted for information on the system.

12. Enter the affiliation of the person who should be contacted for information on the system.

13. Enter the mail address for the person who should be contacted for information on the system.

14. Enter the express package delivery address for the person who should be contacted for information on the system.

15. Enter the e-mail address for the person who should be contacted for information on the system.

16. Enter the phone number for the person who should be contacted for information on the system. 
17. Enter the fax number for the person who should be contacted for information on the system.

\section{$\underline{\text { Section B }}$}

1. Enter a description of the system, its principles of operation, and optional modes for assay.

2. Enter the identifier(s) for the written standard operating procedure(s) (SOP $[\mathrm{s}])$ that are used to operate the system for waste assay.

3. For each mode of quantitation that may be used for the system, enter the quantitation principle, mode identification, the criteria for selecting the subject modes, and the source of isotopic data used for that mode. Sources of isotopic data may be coded:

$\mathrm{P}=$ isotopic data are produced as an integral part of the primary quantitative assay, e.g., gamma spectrometric methods used for both the quantitative and isotopic data.

$\mathrm{S}=$ isotopic data are produced from a secondary method, e.g., the primary quantitation is by passive neutron assay but isotopic ratios are obtained from an independent gamma spectrometric method.

$\mathrm{AK}=$ isotopic data are obtained from acceptable knowledge of the waste stream or container.

\section{$\underline{\text { Section C }}$}

1 to 5. Check off Yes or No to each question. For each "Yes," indicate the applicable mode(s) from section B.3.

6. Enter the possible mode(s) from section B.3 for each combination of activity range and waste type. Enter "NA" for combinations for which the system will not be used. If explanatory information is required, enter a number in the comments column and add the number and explanation to section D. For example, a system may have a calibration cut-off that falls at the midpoint of a test range. This may be indicated by accepting the range, but indicating the true numerical limit in a comment.

7 to 9 . Enter the values and units for any limits on system tests that, if exceeded, would prevent the system from assaying a PDP box.

\section{$\underline{\text { Section D }}$}

Add any comments necessary to explain answers in any prior sections or supplemental information useful to the NDA PDP coordinator in planning effective PDP tests for the system. Attach continuation sheets as needed.

\section{$\underline{\text { Section E }}$}

Enter the requested information for the person submitting the registration form.

Sign and forward the original of the form to the NDA PDP coordinator. 


\section{PERFORMANCE DEMONSTRATION PROGRAM FOR NDA OF BOXED WASTES NDA SYSTEM REGISTRATION FORM}

\begin{tabular}{|c|c|c|c|}
\hline \multicolumn{4}{|c|}{ A. SYSTEM IDENTIFICATION } \\
\hline \multicolumn{4}{|l|}{ 1. Official System Name: } \\
\hline 2. Acronym & & \multicolumn{2}{|c|}{ Coordinator Use Only } \\
\hline 3. No. of identical systems: & & System ID: & \\
\hline 4. Unit No. (this system): & & Group No.: & \\
\hline 5. Mobility Type: & \multicolumn{3}{|c|}{ Fixed, Permanent $\square \quad$ Transportable, Nonpermanent $\square$} \\
\hline 6. Current Facility Location: & & \multicolumn{2}{|c|}{ 7. On-Site Reference } \\
\hline \multicolumn{4}{|l|}{ 8. System Owner: } \\
\hline \multicolumn{4}{|l|}{ 9. System Operator: } \\
\hline 10. Primary Contact Name: & & 15. E-Mail: & \\
\hline 11. Title: & & 16. Phone: & \\
\hline 12. Affiliation: & & 17. Fax: & \\
\hline \multicolumn{4}{|l|}{ 13. Postal Address: } \\
\hline 14. Express Package Address: & & & \\
\hline
\end{tabular}

\begin{tabular}{|c|c|c|c|c|}
\hline \multicolumn{5}{|c|}{ B. Method Summary } \\
\hline \multicolumn{5}{|c|}{ 1. Brief Description of Method: } \\
\hline \multicolumn{5}{|c|}{ 2. Associated SOP Identification(s): } \\
\hline \multicolumn{5}{|c|}{ 3. For each quantitative mode in which the system is used, complete the following: } \\
\hline & $\begin{array}{l}\text { 3a. Principle of } \\
\text { Quantitation }\end{array}$ & 3b. Mode & 3c. Criteria for Selection & $\begin{array}{l}3 \mathrm{~d} \text {. Source of } \\
\text { Isotopic Data }\end{array}$ \\
\hline \multicolumn{5}{|l|}{$\begin{array}{l}\text { Quantitative } \\
\text { Mode 1 }\end{array}$} \\
\hline \multicolumn{5}{|l|}{$\begin{array}{l}\text { Quantitative } \\
\text { Mode } 2\end{array}$} \\
\hline \multicolumn{5}{|l|}{$\begin{array}{l}\text { Quantitative } \\
\text { Mode } 2\end{array}$} \\
\hline $\begin{array}{l}\text { Quantitative } \\
\text { Mode } 3\end{array}$ & & & & \\
\hline
\end{tabular}




\section{Scope and Limitations on System Use:}

\begin{tabular}{|c|c|c|c|c|c|c|}
\hline & & & & YES & $\mathrm{NO}$ & If YES, Mode No(s): \\
\hline $\begin{array}{l}\text { 1. Will the } \\
\text { containin }\end{array}$ & $\begin{array}{l}m \text { be used to ce } \\
s \text { than } 0.01 \text { curi }\end{array}$ & $\begin{array}{l}\text { aste as TRU, fo } \\
\text { RU isotopes? }\end{array}$ & & & & \\
\hline 2. Will the $\mathrm{s}$ & $\mathrm{m}$ be used for $\mathrm{w}$ & ontaining weap & onium? & & & \\
\hline 3. Will the $\mathrm{s}$ & $\mathrm{m}$ be used for $\mathrm{w}$ & containing heat & Im? & & & \\
\hline 4. Will the $s$ & $\mathrm{~m}$ be used for $\mathrm{w}$ & ontaining unkn & tios? & & & \\
\hline 5. Will the $\mathrm{s}$ & $\mathrm{m}$ be used for $\mathrm{w}$ & ontaining uran & & & & \\
\hline $\begin{array}{l}\text { 6. Indicate } t \\
\text { multiple }\end{array}$ & $\begin{array}{l}\text { nges and waste } \\
\text { titative modes, }\end{array}$ & $\begin{array}{l}\text { for which the s } \\
\text { to indicate the }\end{array}$ & $\begin{array}{l}\text { articipat } \\
\text { le(s) for }\end{array}$ & $\begin{array}{l}\mathrm{n} \text { in } \\
\operatorname{ach} \mathrm{c}\end{array}$ & PDP. & or systems with \\
\hline $\begin{array}{l}\text { Activity } \\
\text { range }\end{array}$ & $\begin{array}{l}\text { Range in } \\
\text { alpha-curies }^{\mathrm{a}}\end{array}$ & Combustibles & Metals & & & Comment No. \\
\hline Low & $>0$ to 0.02 & & & & & \\
\hline Mid-Low & $>0.02$ to 0.2 & & & & & \\
\hline Mid-High & $>0.2$ to 2.0 & & & & & \\
\hline High & $>2.0$ & & & & & \\
\hline
\end{tabular}

a. Possible range of TRU activity in a box or SWB; units are curies of alpha-emitting TRU isotopes with half-lives greater than 20 years.

7. Indicate the maximum activity permissible (including units) for testing the system due to calibration, radiological safety, or administrative limits:

8. Indicate the maximum weight permissible (including units) for testing the system due to calibration, safety, or administrative limits:

9. Indicate any other limitations on system tests: (Explanation in Comment No. .)

D. Comments. Please add any information relative to participation of this system in the NDA Box PDP:

\section{E. Please register the system described in this application for participation in future cycles of the NDA Box} PDP. It is understood that system tracking, test design, approval conditions, participation requirements, and audit follow-up may be based on the information supplied in this application.

\begin{tabular}{||l|l|l||}
\hline Typed Name: & Signature: & Date: \\
\hline Phone Number: & E-Mail: & \\
\hline \hline
\end{tabular}

F: Disposition: (Coordinator Use Only.) 


\section{APPENDIX C}

\section{Statistical Basis for Scoring Criteria}




\title{
APPENDIX C \\ STATISTICAL BASIS FOR SCORING CRITERIA
}

\author{
C1. Definitions
}

\section{Limits and bounds}

In this discussion, two types of bounds or limits are referred to: (1) those specified in the QAO's that define the acceptable ranges for precision and accuracy of an assay system, and (2) the endpoints of 95 percent confidence intervals calculated for the actual precision or accuracy of a system. While the terms "limits" and "bounds" can be used interchangeably, to avoid confusion this discussion uses the term "limits" only in reference to the WAC/PDP acceptable performance criteria. Similarly the term "bounds" is used only to describe the endpoints of calculated 95 percent confidence intervals.

\section{Point estimate}

A point estimate is the best single value estimate for the parameter of interest. Point estimates contrast with confidence bound estimates, which are interval estimates (since they delineate bounds on confidence intervals). For accuracy (used to estimate bias) the point estimate is the calculated percent recovery. For precision the point estimate is the percent relative standard deviation.

\section{C2. Performance Criteria}

For a noninterfering matrix, the WAC QAO's (table C-1, column 2) specify acceptable limits for the measured precision of an NDA system based on 15 replicate determinations. Precision is measured by percent relative standard deviation. The measured precision based on 15 replicates is only an approximation of the true system precision. Hence implicit in each WAC QAO limit for the measured precision is a corresponding 95 percent upper confidence bound on the true system precision. These bounds are stated explicitly in table C-1, column 3. Precision criteria for the PDP tests, derived in relation to the upper confidence bounds in column 3, as described below, are given in columns 4 and 5 .

The percent recovery criteria for accuracy from the WAC have been adopted for the PDP tests for the noninterfering matrix (column 6). The PDP criteria for bias for the interfering matrices (column 7) are less restrictive than the noninterfering case.

\section{Precision criteria for noninterfering waste matrices}

The true precision and accuracy of an assay system are unknown. We use test data to estimate performance. The more data we have the better our estimates. The PDP criteria for measured precision in table $\mathrm{C}-1$, column 4, were derived based on the fact that obtaining the same upper confidence bounds listed in column 3, but with only six replicates in the PDP, requires that the acceptable measured precision values be adjusted downward compared to that allowable for 15 replicates. 
Table C-1. Performance Criteria for the NDA Box PDP

\begin{tabular}{|c|c|c|c|c|c|c|}
\hline \multirow[t]{2}{*}{$\begin{array}{l}\text { Activity } \\
\text { Range in } \\
\alpha \text {-Curies }\end{array}$} & \multirow[t]{2}{*}{$\begin{array}{l}\text { QAO for } \\
\text { Precision } \\
\text { (@15 } 15 \\
\text { Replicates) }\end{array}$} & \multirow[t]{2}{*}{$\begin{array}{c}\text { Maximum } \\
\text { Allowable } \\
\text { Precision } \\
(95 \% \text { CB } \\
\text { of QAO) }\end{array}$} & \multicolumn{2}{|c|}{$\begin{array}{l}\text { Maximum Measured } \\
\text { PDP Precision } \\
\text { (@6 Replicates) }\end{array}$} & \multicolumn{2}{|c|}{$\begin{array}{c}\text { Maximum PDP QAO's for Bias } \\
\text { (Values for } \% \mathrm{R}_{\mathrm{L}} \text { and } \% \mathrm{R}_{\mathrm{U}} \\
\text { for Use in equation } \mathrm{C} 11) \\
\text { (@6 Replicates) }\end{array}$} \\
\hline & & & Noninterfering & Interfering & Noninterfering & Interfering \\
\hline $\begin{array}{c}>0 \text { to } \\
0.02\end{array}$ & 0.20 & 0.292 & 0.14 & "0.16 & $\begin{array}{l}\text { Low: } 0.70 \\
\text { High: } 1.30\end{array}$ & $\begin{array}{l}\text { Low: } 0.40 \\
\text { High: } 1.60\end{array}$ \\
\hline $\begin{array}{c}>0.02 \text { to } \\
0.2\end{array}$ & 0.15 & 0.219 & 0.105 & 0.12 & $\begin{array}{l}\text { Low: } 0.70 \\
\text { High: } 1.30\end{array}$ & $\begin{array}{l}\text { Low: } 0.40 \\
\text { High: } 1.60\end{array}$ \\
\hline $\begin{array}{c}>0.2 \text { to } \\
2.0\end{array}$ & 0.10 & 0.146 & 0.07 & 0.12 & $\begin{array}{l}\text { Low: } 0.70 \\
\text { High: } 1.30\end{array}$ & $\begin{array}{l}\text { Low: } 0.40 \\
\text { High: } 1.60\end{array}$ \\
\hline$>2.0$ & 0.05 & 0.073 & 0.035 & 0.06 & $\begin{array}{l}\text { Low: } 0.70 \\
\text { High: } 1.30\end{array}$ & $\begin{array}{l}\text { Low: } 0.40 \\
\text { High: } 1.60\end{array}$ \\
\hline
\end{tabular}

For example, when only six replicates are used, a measured value of 18 percent for the relative standard deviation of an assay system in the low activity range, even though it is less than the 20 percent allowable with 15 replicates, does not necessarily mean the implicit QAO of an upper confidence bound of 29.2 percent has been met. In fact, the 95 percent one-sided upper confidence bound for this six- replicate example is approximately 38 percent--considerably higher than the allowable limit. Hence the allowable measured precision with only six replicates must be lower than that for 15 replicates.

Since the confidence bounds for percent relative standard deviation depend only on the standard deviation itself (assuming a fixed sample size), it is possible to determine ahead of time exactly how large a calculated PDP point estimate value can be and still have an associated upper one- sided 95 percent confidence bound that meets the criteria in column 3 of table $\mathrm{C}-1$. The fourth column in table $\mathrm{C}-1$ gives these maximum point estimate values. Thus it is this column to which the calculated PDP point estimate for relative standard deviation of measurements on noninterfering matrices should be compared. (Exactly how the values for interfering matrices in column 4 were obtained are described below.) Note that comparing the PDP point estimate to the value in column 4 is exactly equivalent to comparing the associated upper one-sided 95 percent confidence bound to the value in column 3 . That is, a PDP point estimate of the value indicated in column 4 will have a 95 percent upper one-sided confidence bound equal to the value in column 3. (Similar point estimate columns for instrument bias and total bias can not be calculated since the confidence bounds for percent recovery depend on both the percent recovery point estimate and the estimated standard deviation.)

\section{C.3 Calculating Limits for Measured Relative Precision}

The limits specified in column 4 for relative precision (measured by relative standard deviation) are derived from confidence interval calculations for the variance (i.e., the square of the standard deviation) of a distribution. The derivation is described below. But first a word of caution is in order. There is much variation in the notation used from one statistics book to another in describing confidence intervals for variances and in how tables of chi-square critical values are listed. In particular, what is defined as (1 $-\alpha$ ) below is defined as $\alpha$ in some texts. Furthermore, some chi-square tables give critical values based on upper-tail probabilities while others give them based on lower-tail probabilities.

\section{General derivation}


Let $\sigma^{2}=$ the true variance and let $1-\alpha=$ the desired confidence value. Furthermore, let $s^{2}=$ the sample standard deviation, and $\mathrm{X}_{\alpha, \mathrm{n}-1}^{2}$ be the critical value of a chi-square distribution with $\mathrm{n}-1$ degrees of freedom above which $\alpha \%$ of the distribution lies (that is, the critical value for the upper $\alpha \%$ tail of the distribution). Then, assuming a normal distribution, a two-sided $(1-\alpha) \%$ confidence interval for the true variance is (e.g., Anderson 1987)

$\frac{(\mathrm{n}-1) \mathrm{s}^{2}}{\chi_{\alpha / 2, \mathrm{n}-1}^{2}}<\sigma^{2}<\frac{(\mathrm{n}-1) \mathrm{s}^{2}}{\chi_{1-\alpha / 2, \mathrm{n}-1}^{2}}$.

Based on this formula for the two-sided interval, the upper one-sided $(1-\alpha) \%$ confidence bound is

$\sigma^{2}<\frac{(\mathrm{n}-1) \mathrm{s}^{2}}{\chi_{1-\alpha, \mathrm{n}-1}^{2}}$

from which the corresponding bound for the true percent relative standard deviation can be calculated as

$$
\frac{\sigma}{\mu} 100 \%<\sqrt{\frac{(\mathrm{n}-1) \frac{\mathrm{s}^{2}}{\mu^{2}}}{\chi_{1-\alpha, n-1}^{2}}} 100 \%
$$

where $\mu$ is the true mean of the distribution.

For the PDP tests, $n=6$ and $\mathrm{X}_{1-\alpha, \mathrm{n}-1}^{2}=\mathrm{X}_{.05,5}^{2}=1.145$ in equation C3. Substituting these values and the reference (or true) value of the PDP sample for $\mu$ in this formula gives an approximate upper one-sided 95 percent confidence bound for the percent relative standard deviation. If desired, this upper confidence bound can be directly compared to the numbers in column 3 of table C-1 to determine if an assay system has met the relative precision criteria.

The numbers in column 4 of table C-1 (to which the point estimates rather than the upper confidence bounds can be compared) are derived by comparing the right-hand side of equation $\mathrm{C} 3$ to the appropriate number in column 3 of table $\mathrm{C}-1$ and solving for $\mathrm{s} / \mu$. As an example, for the low activity range this calculation begins with the $\mathrm{QAO}$ required inequality

$$
\sqrt{\frac{(\mathrm{n}-1) \frac{\mathrm{s}^{2}}{\mu^{2}}}{\chi_{1_{-\alpha}, \mathrm{n}_{-} 1}^{2}}} 100 \%<29.2 \%
$$

Solving for $\mathrm{s} / \mu$ gives

$$
\frac{\mathrm{s}}{\mu} 100 \%<\sqrt{\frac{(0.292)^{2} \chi_{1-\alpha, \mathrm{n}-1}^{2}}{\mathrm{n}-1}} 100 \%
$$

which for six samples and 95 percent confidence as specified in the PDP gives 


$$
\frac{\mathrm{s}}{\mu} 100 \%<\sqrt{\frac{(0.292)^{2}(1.145)}{5}} 100 \%=14 \%
$$

Again, substituting the reference (or true) value of the PDP sample for $\mu$ indicates that a calculated relative standard deviation of 14 percent or less meets the QAO for relative precision in the low activity range. Since the chi-square value and $n$ are the same for all activity levels, the column 4 values for the other activity levels are obtained simply by substituting the appropriate value from column 3 in place of 0.292 in equation C6.

\section{Precision Criteria for Interfering Waste Matrices}

The WAC QAO's are specified for a substantially noninterfering matrix. To determine rational precision scoring criteria for the interfering cases, it was necessary to establish some relationship to program objectives that can be used as a basis for the PDP criteria for the interfering waste matrices. There are certain program-defined limits for which assay systems are used to ensure compliance. In particular, there are the 200 fissile gram equivalent (FGE) material limits for 55-gallon containers and the TRU waste activity definition used to discriminate TRU waste from low- level radioactive waste (LLW). At the high end, the precision of the assay system should be reasonable for waste containers approaching the 200 FGE limit to ensure that an excessive number of containers do not exceed the limit at the 95 percent confidence level. Similarly, the waste assay system should be sufficiently precise for containers of low TRU mass loading (i.e., in the vicinity of the $100 \mathrm{nCi} / \mathrm{gram}$ alpha activity criterion) to ensure that an unacceptable number of containers of TRU waste are not classified as LLW.

As a convenient base for determining precision criteria for interfering waste matrix containers, the compliance points in table C-1 of the WAC (DOE 1999) were used. For the low activity range the nominal compliance point for meeting the WAC precision and bias criteria is $100 \mathrm{mg}$ of weapons grade plutonium (WG Pu). An acceptable assay system should be capable of detecting and quantifying TRU waste in 55-gallon waste containers at a level of $35 \mathrm{mg} \mathrm{WG} \mathrm{Pu.} \mathrm{When} \mathrm{assaying} \mathrm{a} \mathrm{container} \mathrm{at} \mathrm{the}$ compliance point of $100 \mathrm{mg} \mathrm{WG} \mathrm{Pu}$, we would like to be sure at the 95 percent confidence level that the assay system will not return a value less than $35 \mathrm{mg} \mathrm{WG} \mathrm{Pu}$. This provides reasonable protection against classifying TRU waste as LLW. Based on this rationale, two standard deviations would correspond to 65 $\mathrm{mg}(100 \mathrm{mg}-35 \mathrm{mg})$. One relative standard deviation would therefore be $32.5 \mathrm{mg} / 100 \mathrm{mg}$ or 0.325 . By substituting 0.325 in place of 0.292 in equation C6, we obtain a value of 0.155 (rounded up to 0.16 ) for the measured precision criterion for six replicate determinations of an interfering matrix container in the low activity range.

Using similar reasoning, a precision criterion can be assigned to the high-mass region. In this case the nominal compliance point is $160 \mathrm{~g} \mathrm{WG} \mathrm{Pu}$. When assaying a container at the compliance point of $160 \mathrm{~g}$ WG $\mathrm{Pu}$, we would like to be sure at the 95 percent confidence level that the assay system will not return a value greater than $200 \mathrm{~g} \mathrm{WG} \mathrm{Pu}$. This provides reasonable protection against mistakenly classifying a TRU waste SWB as not shippable when in fact it does not exceed the limit. Based on this rationale, two standard deviations would correspond to 40 grams $(200 \mathrm{~g}-160 \mathrm{~g})$. One relative standard deviation would therefore be $20 \mathrm{~g} / 160 \mathrm{~g}$ or 0.125 . By substituting 0.125 in place of 0.292 in equation $\mathrm{C} 6$, we obtain a value of 0.0598 (rounded up to 0.06) for the measured precision criteria for six replicate determinations of an interfering matrix container in the high activity range.

No compelling programmatic objectives argue for specific precision limits for the low-middle and highmiddle ranges, although some thermal limits will fall into these ranges for some waste forms. Therefore, it was felt that arbitrary limits based on consistency and continuity in the use of the assay systems would 
be adequate for these ranges. The precision criteria for the low-middle and high-middle ranges were set at 0.12 for the $\% \mathrm{RSD}$ of six replicate determinations.

\section{C.4 Calculating Confidence Bounds for Instrument Bias and Total Bias}

To compare an assay system's performance to the requirements for bias for the noninterfering and interfering test conditions requires calculating the 95 percent two-sided confidence bounds for the true parameter using the sample data. Based on a $t$-distribution, the $(1-\alpha) \%$ two-sided confidence bounds for the true mean assay system mean are (assuming a normal distribution):

$$
\overline{\mathrm{x}}-\mathrm{t}_{1-\alpha / 2, \mathrm{n}-1} \frac{\mathrm{s}}{\sqrt{\mathrm{n}}}<\mu<\overline{\mathrm{x}}+\mathrm{t}_{1-\alpha / 2, \mathrm{n}-1} \frac{\mathrm{s}}{\sqrt{\mathrm{n}}}
$$

In terms of relative percent recovery, the bounds are

$$
\frac{\overline{\mathrm{x}}-\mathrm{t}_{1-\alpha / 2, \mathrm{n}-1} \frac{\mathrm{s}}{\sqrt{\mathrm{n}}}}{\mu_{0}} 100 \%<\frac{\mu}{\mu_{0}} 100 \%<\frac{\overline{\mathrm{x}}+\mathrm{t}_{1-\alpha / 2, \mathrm{n}-1} \frac{\mathrm{s}}{\sqrt{\mathrm{n}}}}{\mu_{0}} 100 \%
$$

where $\mu_{0}$ is the known (or accepted) value. These lower and upper bounds must be greater than $\% \mathrm{R}_{\mathrm{L}}$ and less than $\% \mathrm{R}_{\mathrm{U}}$, respectively, where $\% \mathrm{R}_{\mathrm{L}}$ and $\% \mathrm{R}_{\mathrm{U}}$ are the appropriate lower and upper bounds from table C-1 (column 6 or 7). As before, these calculated lower and upper bounds can be compared with the limits specified in table C-1. Equivalently, bounds for the point estimates for percent recovery can be obtained by solving the required inequalities for percent recovery.

The required inequalities are

$$
\frac{\overline{\mathrm{x}}-\mathrm{t}_{1-\alpha / 2, \mathrm{n}-1} \frac{\mathrm{s}}{\sqrt{\mathrm{n}}}}{\mu_{0}} 100 \%>\% \mathrm{R}_{\mathrm{L}} \text { and } \frac{\overline{\mathrm{x}}+\mathrm{t}_{1-\alpha / 2, \mathrm{n}-1} \frac{\mathrm{s}}{\sqrt{\mathrm{n}}}}{\mu_{0}} 100 \%<\% \mathrm{R}_{\mathrm{U}}
$$

which, on solving for relative percent recovery gives

$$
\% \mathrm{R}_{\mathrm{L}}+\frac{\mathrm{t}_{1-\alpha / 2, \mathrm{n}-1} \frac{\mathrm{s}}{\sqrt{\mathrm{n}}}}{\mu_{0}} 100 \%<\frac{\overline{\mathrm{x}}}{\mu_{0}} 100 \%<\% \mathrm{R}_{\mathrm{U}}-\frac{\mathrm{t}_{1-\alpha / 2, \mathrm{n}-1} \frac{\mathrm{s}}{\sqrt{\mathrm{n}}}}{\mu_{0}} 100 \%
$$


With six samples, $n=6$, and the corresponding $t$ value (for 95 percent two-sided confidence bounds) is 2.571. So the equations simplify to

$$
\% \mathrm{R}_{\mathrm{L}}+\frac{1.05 \mathrm{~s}}{\mu_{0}} 100 \%<\frac{\overline{\mathrm{x}}}{\mu_{0}} 100 \%<\% \mathrm{R}_{\mathrm{U}}-\frac{1.05 \mathrm{~s}}{\mu_{0}} 100 \% \text {. }
$$

\section{REFERENCES}

Anderson, R. L. 1987. Practical Statistics for Analytical Chemists. New York, Van Nostrand Reinhold.

DOE. 1999. Waste Acceptance Criteria for the Waste Isolation Pilot Plant. DOE/WIPP-069, Current Revision. Carlsbad, New Mexico, Waste Isolation Pilot Plant, U.S. Department of Energy. 


\section{APPENDIX D}

\section{Specifications for Radioactive PDP Standards}




\section{APPENDIX D}

\section{SPECIFICATIONS FOR RADIOACTIVE PDP STANDARDS}

This appendix delineates the general characteristics of the PDP standard design. Several versions of standards are used in the program, although all have the same external dimensions to properly fit the

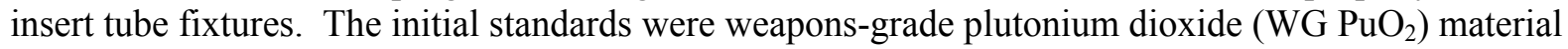
uniformly mixed in diatomaceous earth that was encapsulated in a dual stainless-steel cylinder configuration. The bottom end of both the outer and inner seamless tubes have electron beam welded endcaps. The $\mathrm{WG} \mathrm{PuO}_{2}$ /diatomaceous earth mixture was dispensed into the inner cylinder, packed and stabilized with a press fitted frit 0.25 inches high. The top endcap was then pressed in and welded using a tungsten inert gas method. The assembled inner tube was inserted into the outer tube and the top endcap is similarly welded in place. An assembled PDP standard is illustrated in figure D-1. Other standards in the PDP use the radioactive materials discussed in section 5.1. Some standards use an inert matrix other than diatomaceous earth, such as a carbon felt matrix to provide for more secure immobilization and/or precise placement of the radioactive material. One set of standards used the same encapsulation method described above but substituted a dual zircalloy cylinder configuration in lieu of the stainless steel.

The dimensional and material attributes of the PDP standard were derived as a function of PDP objectives, nondestructive waste assay system response characteristics, and practicalities of fabrication. A complete PDP standard specification with supporting analyses is provided in the Lockheed Martin Idaho Technologies Company document, Performance Demonstration Program for Nondestructive Assay for the TRU Waste Characterization Program, Initial Cycle Source Design (INEL-94/0104).

The as-specified PDP standard configuration complies with the following general requirements.

1. PDP standards must be physically stable and invariant with time in a well-defined geometry.

2. The PDP standard configuration must facilitate convenient loading of the standards into the PDP matrix container.

3. The PDP standard dimensions must allow for the simulation of multiple source spatial geometries within the PDP matrix container.

4. The PDP standard encapsulation integrity must comply with all applicable standards and be acceptable for transportation and storage at participating sites.

5. The PDP standard design must accommodate available fabrication technologies at a reasonable cost. 


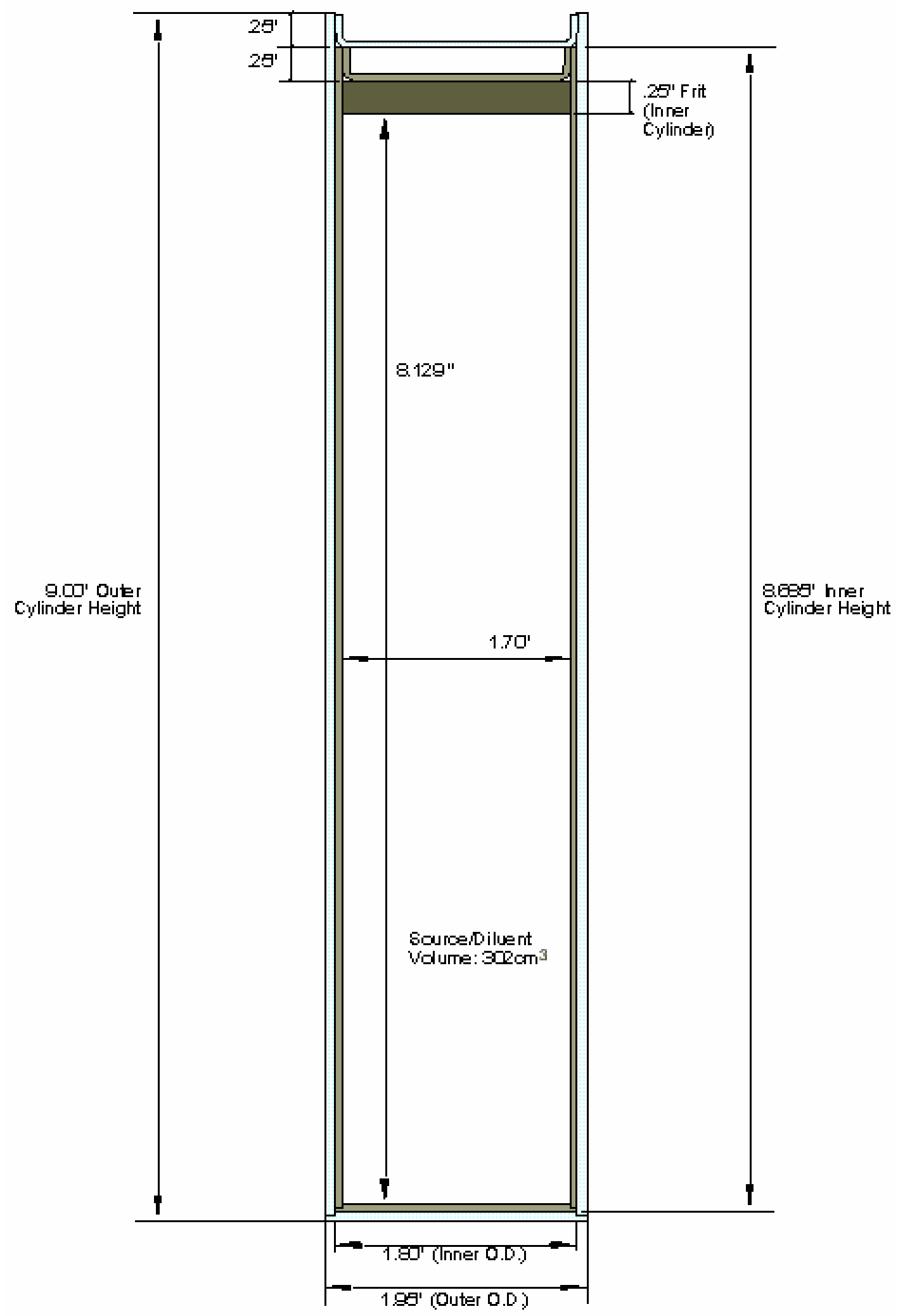

Figure D-1. PDP Standard Configuration 


\section{APPENDIX E}

\section{SWB Matrix Surrogate Specifications}




\section{APPENDIX E SWB Matrix Surrogate Specifications}

This appendix provides a description of the SWB matrix surrogates used for the NDA Box PDP. These matrix surrogates were designed and delivered for the first PDP cycle for boxed wastes. Illustrations are provided specifying dimensional and material attributes. The SWB matrix surrogate configuration was based on the PDP Plan objectives, that is, establish performance characteristics for nondestructive waste assay systems and provide for a means to assess system comparability. Assessment of performance required a flexible system for varying the matrix to verify fundamental calibrations and algorithms used to compensate for waste characteristics affecting the phenomena.

The SWB matrix surrogate configuration includes provisions to install two sizes of matrix inserts in addition to allowing for the convenient introduction and precise location of PDP standards within the box surrogate volume. Figure E-1 illustrates the SWB matrix surrogate configuration, providing an overall perspective of the various components.

Aluminum source insert fixtures are provided for each of the 24 insert tube locations (figure E-2). The PDP standard(s) is positioned at a desired vertical location in the source insert fixture through the use of small plunger rods. The insert fixture is then positioned into the source insert tube.

Matrix configurations intended to simulate real waste forms are obtained by filling the various locations within the SWB matrix surrogate housing with inserts containing appropriate quantities of simulated waste materials. Two sizes of matrix inserts are used. A rectangular box insert is used for the interior positions within the housing and external positions on the two straight sides of the SWB (figure E-3). Inserts with two perpendicular, straight sides and one curved side are used on the outside positions adjacent to the two curved sides of the SWB (figure E-4). These simulated matrix materials are matched to the actual wastes in elemental composition as closely as possible. The simulated waste matrix inserts are placed within the box surrogate in a distribution that is appropriate to the test. Matrix spacers are provided when appropriate for use with the matrix surrogate to fill any void space within the source insert fixture not occupied by PDP standard(s), thus ensuring a uniform matrix medium. The NDA PDP coordinator ensures that essential details of each SWB design are communicated to PDP participants prior to its use in any PDP test. 


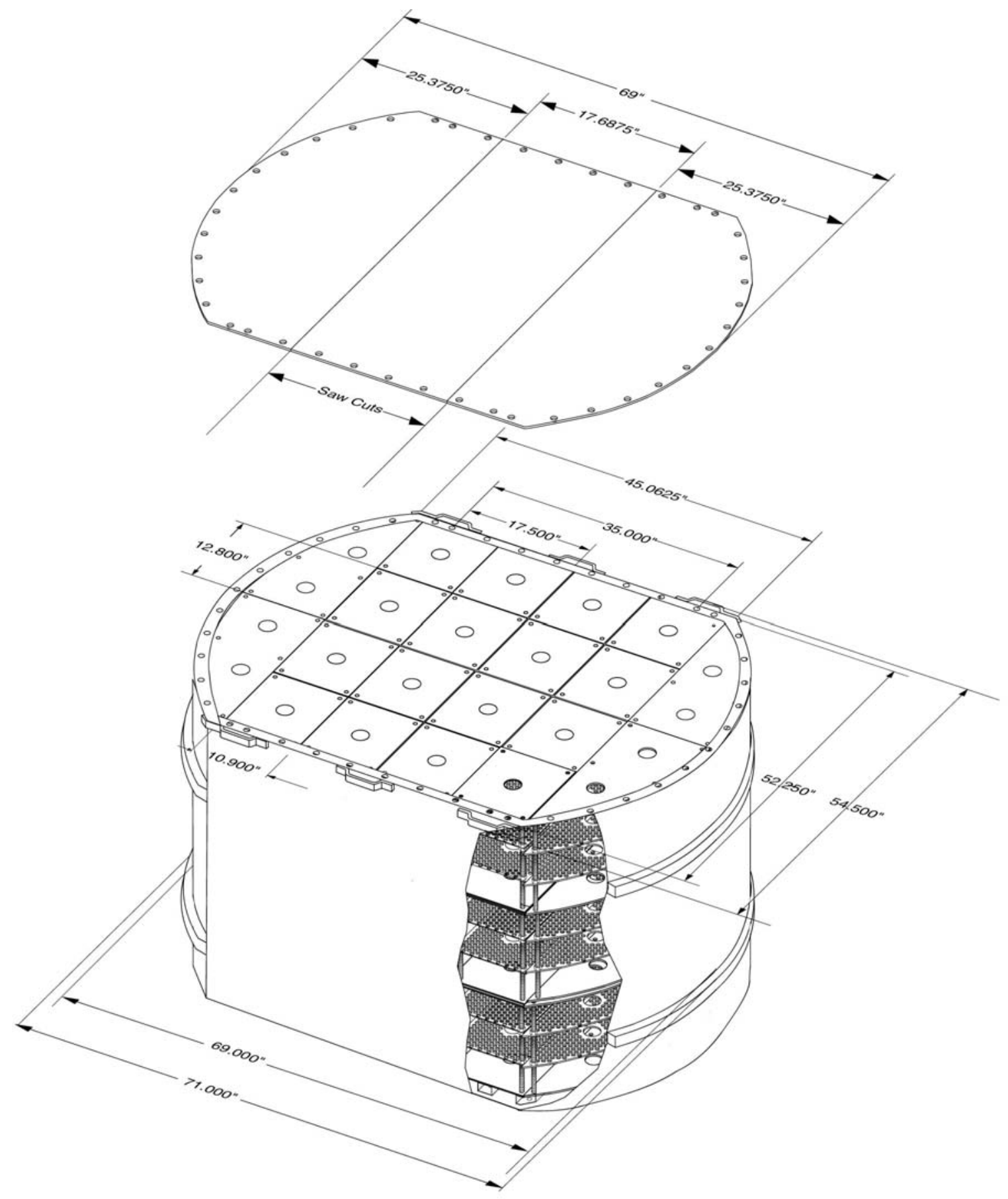

Figure E-1. Cutaway View of SWB Matrix Surrogate 


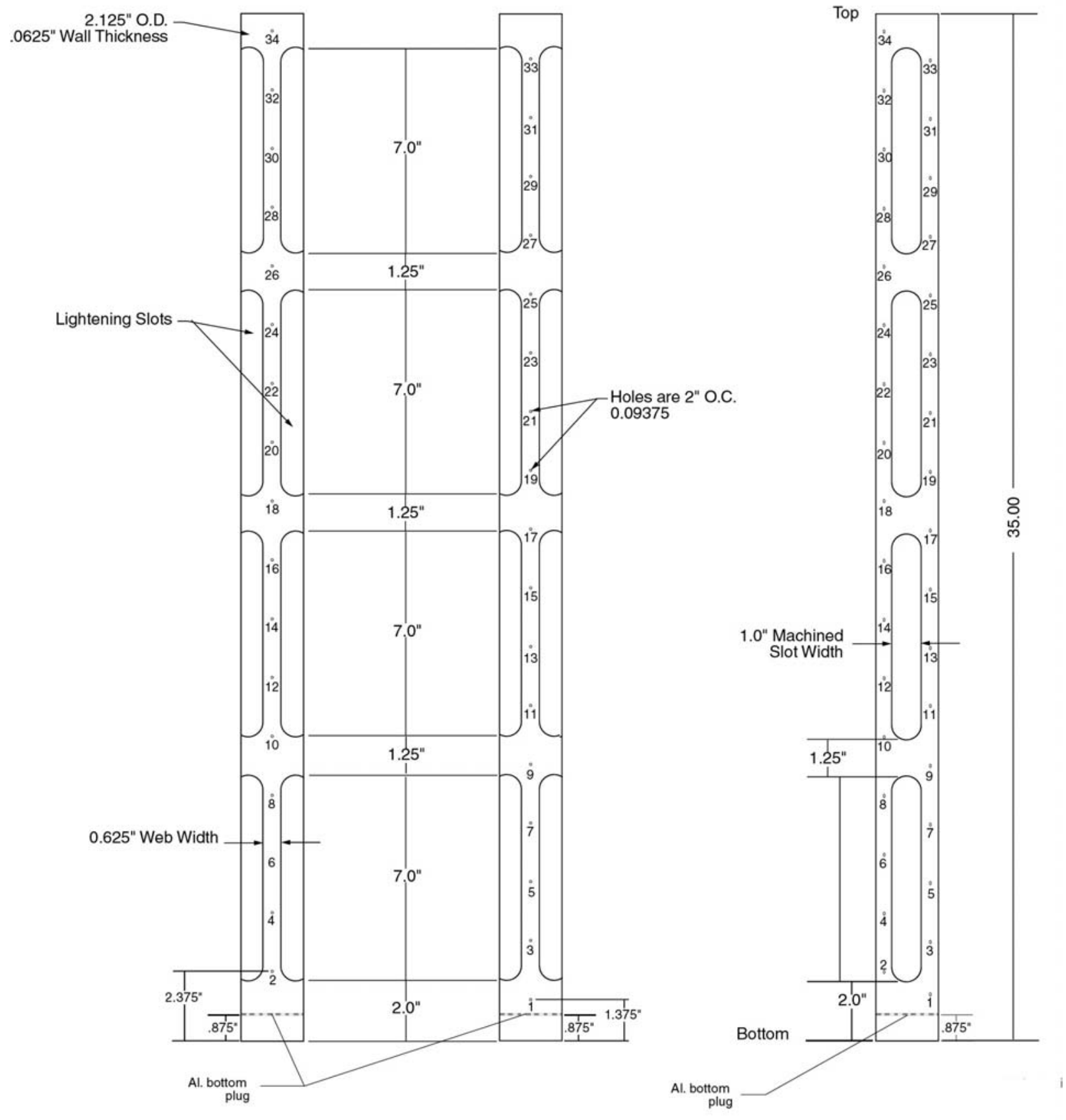

Figure E-2. SWB Matrix Surrogate Source Insert Fixture 


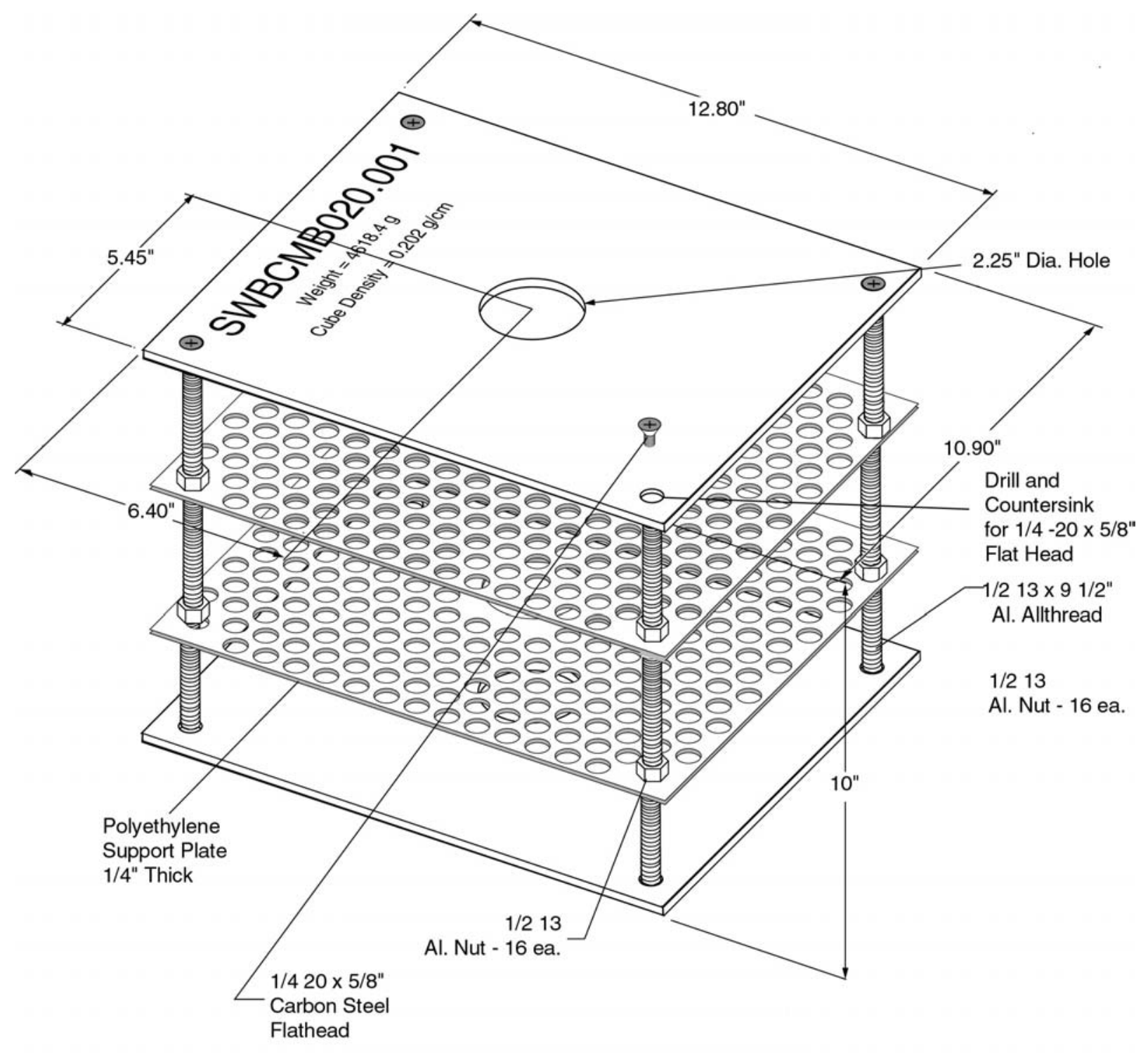

Figure E-3. Typical SWB Cube Matrix Insert 


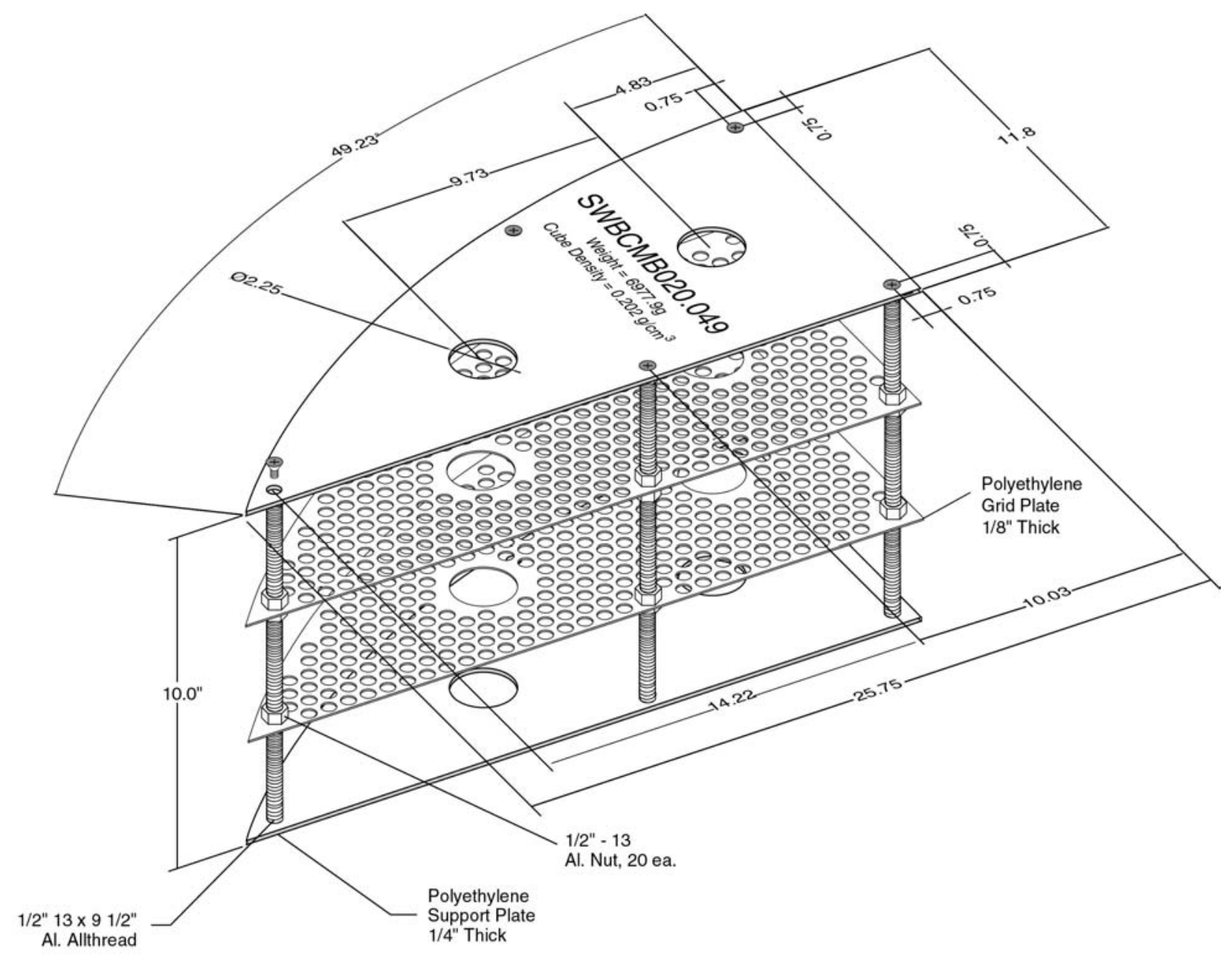

Figure E-4. Typical SWB End Matrix Insert 


\section{APPENDIX F}

\section{Performance Demonstration Program Forms}


PDP Matrix Configuration Form for SWB

\begin{tabular}{|c|c|c|}
\hline Facility Name: & \multicolumn{2}{|c|}{ SWB Number ___ of ___ in this Cycle } \\
\hline PDP Sample ID: & \multicolumn{2}{|l|}{ Tier Number: } \\
\hline Matrix Type: & PDP Distribution $(\mathrm{Mo} / \mathrm{Yr})$ : & Page ___ of \\
\hline
\end{tabular}

\begin{tabular}{|lll}
\hline Authorized: & Dechnical Liaison & \\
\hline
\end{tabular}

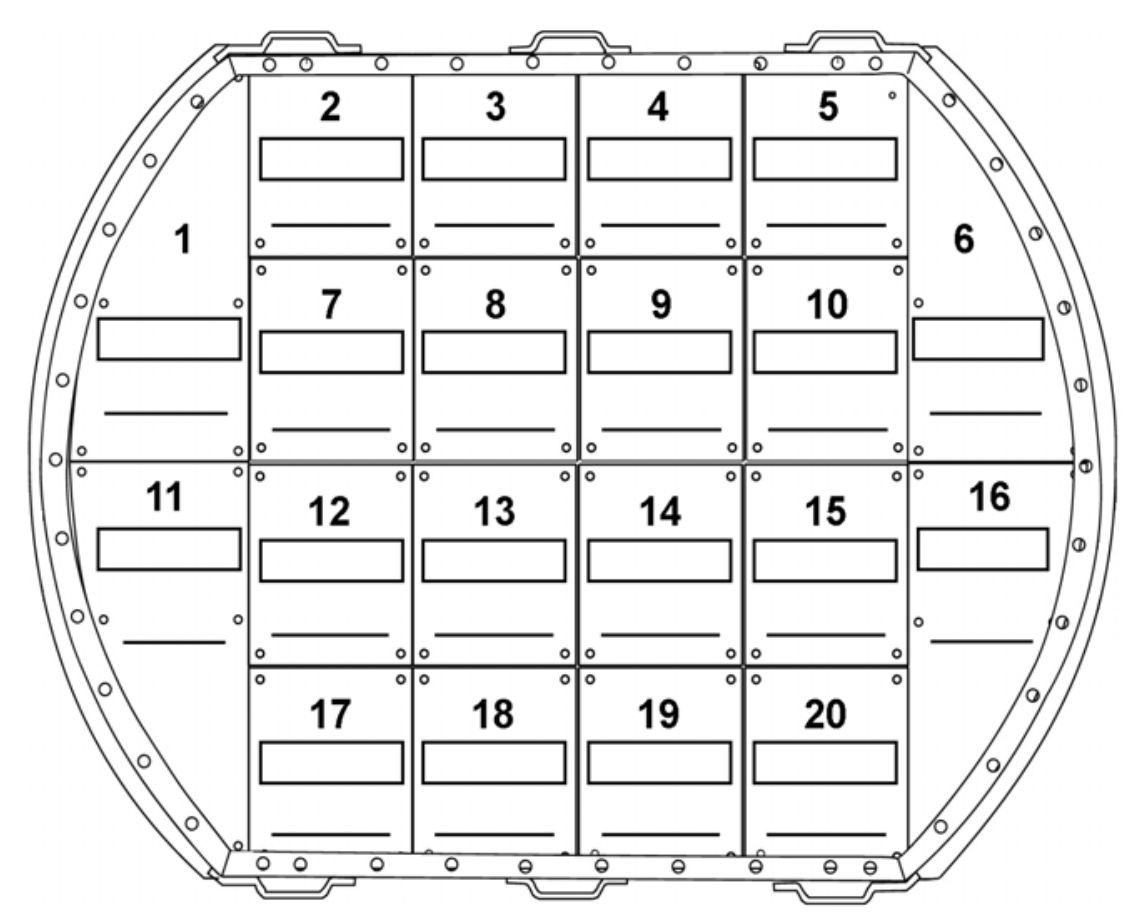

Date:

\section{PDP Matrix Configuration Form for SWB}


PDP Standard Configuration Form for SWB

\begin{tabular}{|l|l|l|}
\hline Facility Name: & SWB Number___of___ in this Cycle \\
\hline PDP Sample ID: & TID Number: & Page__ \\
\hline Matrix Type: & PDP Distribution Mo/Yr): & \\
\hline Authorized: & Technical Liaison & of \\
\hline
\end{tabular}

\begin{tabular}{|c|l|l|l|l|l|l|}
\hline $\begin{array}{c}\text { Source } \\
\text { ID }\end{array}$ & Isotope & Activity & Units & $\begin{array}{c}\text { SWB } \\
\text { Position }\end{array}$ & \multicolumn{2}{|r|}{ Rod Position \# } \\
\hline & & & & & & \\
\hline & & & & & & \\
\hline & & & & & & \\
\hline & & & & & & \\
\hline & & & & & & \\
\hline & & & & & & \\
\hline & & & & & & \\
\hline & & & & & & \\
\hline & & & & & & \\
\hline & & & & & & \\
\hline & & & & & & \\
\hline & & & & & & \\
\hline & & & & & & \\
\hline & & & & & & \\
\hline & & & & & & \\
\hline & & & & & & \\
\hline & & & & & & \\
\hline & & & & & & \\
\hline & & & & & & \\
\hline & & & & & & \\
\hline & & & & & & \\
\hline & & & & & & \\
\hline & & & & & & \\
\hline & & & & & \\
\hline
\end{tabular}

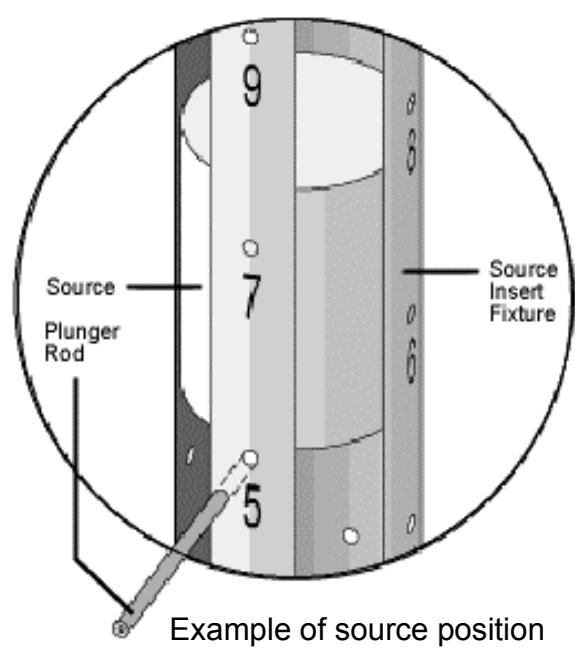

(Rod Position \#5)

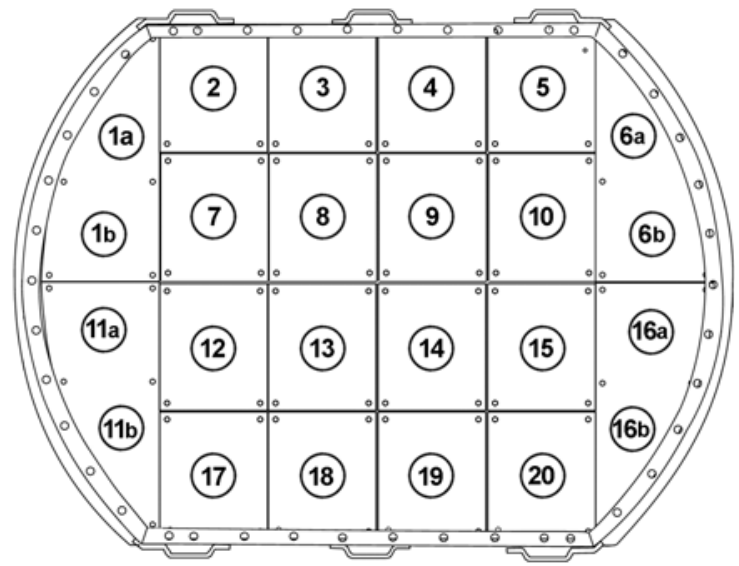

SWB Source Positions 


\section{PDP Sample Custody Form for Nondestructive Assay}

Sample Serial Number:

TID Serial Number:

Assay Site:

Distribution Cycle Number:

Comments:

\section{Sample Preparation}

Sample Preparation Date:

PDP Standards Custodian

Date

Initials

Matrix inserts and standards properly placed:

Matrix TID properly sealed:

Standard Configuration Form attached and sealed:

Standards Configuration Attestant

Date

\begin{tabular}{||l|l|l|l||}
\hline Relinquished By: & Date/Time & Received by: & Date/Time \\
\hline \hline Standards Custodian & & Assay Coordinator & \\
\hline
\end{tabular}

[This is the VTSR. After completion to this point, return a copy to the NDA PDP coordinator.]

\begin{tabular}{||l|l|l|l||}
\hline & & & \\
\hline & & & \\
\hline & & & \\
\hline & & & \\
\hline & & & \\
\hline
\end{tabular}

Final Disposition By:

Date/Time

Disposition

\begin{tabular}{||l|l|ll||}
\hline & & \\
\hline White: NDA PDP coordinator copy on final disposition & $\begin{array}{l}\text { Canary: SPT copy on final disposition } \\
\text { Gold: SPT copy at VTSR }\end{array}$ \\
Pink: NDA PDP coordinator copy at VTSR & ndapdp_cocrv2.frm
\end{tabular}




\section{PERFORMANCE DEMONSTRATION PROGRAM REPORT FORM NONDESTRUCTIVE ASSAY}

Laboratory ID:

PDP Cycle:

Container Serial No.:
Assay Facility:

Supplemental Cycle: Replicate: Laboratory Sample ID:

Final Result Summary

\begin{tabular}{||l|l|l||}
\hline \multicolumn{1}{|c|}{ Parameter } & Final Result & Total Uncertainty (One Standard Deviation) \\
\hline Total ${ }^{239} \mathrm{Pu}$ Fissile equivalent $(\mathrm{g})$ & & \\
\hline Total alpha activity (curies) & & \\
\hline Thermal Power (W) & & \\
\hline
\end{tabular}

\section{Method Summary}

\begin{tabular}{|c|c|c|c|c|c|c|}
\hline & \multirow[b]{2}{*}{ Identification } & \multirow[b]{2}{*}{ Classification } & \multirow{2}{*}{$\begin{array}{c}\text { Associated } \\
\text { SOP }\end{array}$} & \multirow{2}{*}{$\begin{array}{l}\text { Count Time } \\
\text { (min) }\end{array}$} & \multicolumn{2}{|c|}{ Analysis } \\
\hline & & & & & Date & Time \\
\hline Method 1 & & & & & & \\
\hline Method 2 & & & & & & \\
\hline Method 3 & & & & & & \\
\hline
\end{tabular}

Individual Isotope Data

\begin{tabular}{|c|c|c|c|c|c|c|c|c|}
\hline \multirow[b]{2}{*}{ Isotope } & \multirow[b]{2}{*}{ Activity Result } & \multicolumn{2}{|c|}{ Uncertainty } & \multicolumn{4}{|c|}{ Method of Quantitation } & \multirow{2}{*}{$\begin{array}{l}\text { Method } \\
\text { Number } \\
\text { (From } \\
\text { Summary) }\end{array}$} \\
\hline & & Count & Total & Direct & Ratio & $\begin{array}{l}\text { Scaling } \\
\text { Isotope }\end{array}$ & $\begin{array}{l}\text { Ratio } \\
\text { Value }\end{array}$ & \\
\hline${ }^{238} \mathrm{Pu}$ & & & & $\square$ & $\square$ & & & \\
\hline${ }^{239} \mathrm{Pu}$ & & & & $\square$ & $\square$ & & & \\
\hline${ }^{240} \mathrm{Pu}$ & & & & $\square$ & $\square$ & & & \\
\hline${ }^{241} \mathrm{Am}$ & & & & $\square$ & $\square$ & & & \\
\hline & & & & $\square$ & $\square$ & & & \\
\hline & & & & $\square$ & $\square$ & & & \\
\hline & & & & $\square$ & $\square$ & & & \\
\hline
\end{tabular}

COMMENTS:

APPROVAL: 


\section{PDP Sample Disassembly Form for Nondestructive Assay of SWB}

Container Serial Number: TID Serial Number:
Distribution Cycle Number:

Page __ of _.

Sample Disassembly Record

Sample Disassembly Date:

Condition of Seals and Standards

Configuration Form attached and sealed: $\quad$ Yes $\quad \square \quad$ No $\quad \square$

Container TID(s) properly sealed: $\quad$ Yes $\square \quad$ No

Standards properly placed (Cross out if not applicable):

\begin{tabular}{|c|c|c|c|c|c|c|}
\hline Source & 1 & Yes & $\square$ & No & $\square$ & Condition: \\
\hline Source & 2 & Yes & $\square$ & No & $\square$ & Condition: \\
\hline Source & 3 & Yes & $\square$ & No & $\square$ & Condition: \\
\hline Source & 4 & Yes & $\square$ & No & ப & Condition: \\
\hline Source & 5 & Yes & $\square$ & No & $\square$ & Condition: \\
\hline Source & 6 & Yes & $\square$ & No & $\square$ & Condition: \\
\hline Source & 7 & Yes & ] & No & ] & Condition: \\
\hline Source & 8 & Yes & $\square$ & No & $\square$ & Condition: \\
\hline Source & 9 & Yes & $\square$ & No & $\square$ & Conditio \\
\hline Source & 0 & Yes & 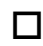 & No & $\square$ & Condit \\
\hline
\end{tabular}

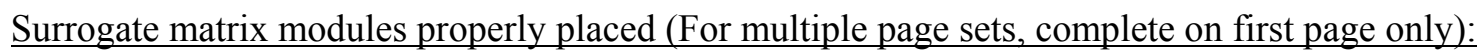

$\begin{array}{lllll}\text { Tier } 1 & \text { Yes } & \square & \text { No } & \square\end{array}$ Condition:

Tier 2 Yes $\square$ No $\square$ Condition:

Tier 3 Yes $\square$ No $\square$ Condition:

Comments:

$\overline{\text { Standards Configuration Attestant }}$

PDP Standards Custodian
Date

Date 